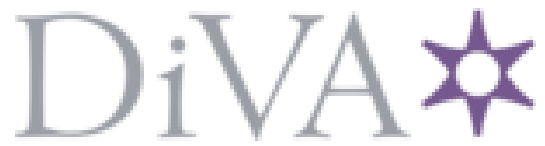

http://www.diva-portal.org

This is the published version of a paper published in Journal of Urban Economics.

Citation for the original published paper (version of record):

Bastani, S., Giebe, T., Miao, C. (2020)

Ethnicity and tax filing behavior

Journal of Urban Economics, 116: 1-16

https://doi.org/10.1016/j.jue.2019.103215

Access to the published version may require subscription.

N.B. When citing this work, cite the original published paper.

Permanent link to this version:

http://urn.kb.se/resolve?urn=urn:nbn:se:lnu:diva-89974 


\title{
Ethnicity and tax filing behavior ${ }^{\text {th }}$
}

\author{
Spencer Bastani ${ }^{\mathrm{a}, \mathrm{b}, \mathrm{c}}$, Thomas Giebe ${ }^{\mathrm{a}, \mathrm{b}, *}$, Chizheng Miao ${ }^{\mathrm{a}, \mathrm{b}}$ \\ ${ }^{a}$ Department of Economics and Statistics, Linnaeus University, Sweden \\ ${ }^{\mathrm{b}}$ Linnaeus University Centre for Discrimination and Integration Studies, Sweden \\ ${ }^{\mathrm{c}}$ CESifo, Germany
}

\section{A R T I C L E I N F O}

\section{JEL classification:}

D31

$\mathrm{H} 21$

$\mathrm{H} 24$

H26

J22

J61

R23

\section{Keywords:}

Deductions

Tax filing

Bunching

Immigrants

Natives

Integration

\begin{abstract}
A B S T R A C T
We analyze differences in tax filing between natives and immigrants, focusing on two empirical examples. First, we study deductions for costs associated with traveling between home and work allowed in the Swedish tax code. Using the total population of commuters within Sweden's largest commuting zone, we find that newly arrived immigrants file substantially less than natives, immigrants with a longer stay behave more like natives, and immigrants with the longest stay file the most, even more than natives. Second, we analyze bunching behavior among the self-employed at a large salient kink point of the Swedish income tax schedule. We find much less bunching among immigrants, even after a long time in the host country, and the largest differences relative to natives in residential areas with a high immigrant concentration. Our findings have implications for the equity and efficiency of the tax system and the spatial patterns of residential and occupational choices for different ethnic groups.
\end{abstract}

\section{Introduction}

In light of increasing globalization and labor mobility, as well as recent waves of migration in Europe, the question of how immigrants interact with the tax systems of their host countries and how they access the benefits of modern welfare states has gained increased relevance. A basic insight is that if, in the government's quest for an equitable and efficient tax system, the tax system becomes too complex and relies too much on the active participation of the taxpayer to correctly provide information to the tax authority, this can result in tax burdens being unequally distributed among individuals with equal economic circumstances. This can lead to unintended welfare consequences, create distortions in economic behavior, and imply that the tax system is viewed as unfair or discriminatory, ultimately affecting its legitimacy. ${ }^{1}$
As knowledge about tax systems is likely to be transmitted within ethnic networks, across generations and through social interactions with experienced (native) tax filers, tax complexity is prone to particularly affect immigrants. Given the relevance of the tax system in most areas of economic life, this has consequences for a range of diverse aspects such as the efficiency of labor markets, cross-country migration incentives, social and spatial mobility, integration, and residential segregation.

In this paper, we document differences in tax filing behavior between natives and immigrants using population-wide administrative data and two specific empirical examples. First, we consider one of the largest Swedish commuting zones, the Stockholm-Uppsala region, and compare how observationally identical natives and immigrants differ with respect to if and how they file for the deduction for commuting cost

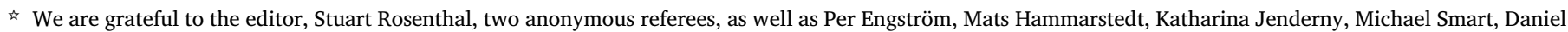
Waldenström and conference participants at the 2019 IIPF conference in Glasgow for helpful comments and discussion.

* Corresponding author.

E-mail addresses: spencer.bastani@lnu.se (S. Bastani), thomas.giebe@lnu.se (T. Giebe), chizheng.miao@lnu.se (C. Miao).

1 A widely acknowledged principle in the design of tax systems is that the government should provide a fiscally equal treatment of "equals". This is not a firmly

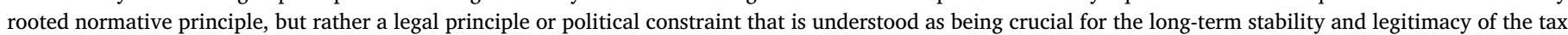
system.
} 
that is allowed in the Swedish tax code. ${ }^{2}$ This commuting deduction, which is the most common deduction in Sweden, implies a reduction in yearly taxable income by an amount equal to the part of an individual's annual expenses for traveling between home and work that exceeds a certain threshold (around $\$ 1000$ ) provided certain eligibility criteria are satisfied. ${ }^{3}$ Second, we study to which extent self-employed natives and immigrants bunch at the largest and most salient kink point of the Swedish personal income tax schedule. This kink is located in the upper middle part of the income distribution, where the marginal tax rate jumps by around 20 percentage points. We use both traditional (unconditional) bunching estimation as well as multivariate regressions where the outcome variable is a dummy indicating whether an individual locates at the kink. Our analysis exploits geographical information about residence and workplace, and the data allows us to differentiate immigrants by the time since arrival in the host country, by their region of origin, and the level of segregation at their residential location. We also complement our study examining differences in tax compliance for the total population.

Our main finding is that there are striking differences in tax filing behavior between natives and immigrants, but also some noteworthy exceptions. Newly arrived immigrant commuters have a substantially lower take-up of the commuting deduction than natives. Immigrants seem to learn over time, and those with a longer stay in Sweden are even more likely to file deductions than natives. Moreover, our bunching analysis reveals that self-employed immigrants are substantially less likely to bunch at the kink, even after several decades in the host country, a result mainly driven by non-European immigrants, and those who live in areas with a high immigrant concentration. Our analysis of tax compliance reveals that immigrants are more likely to miss the declaration deadline and to be fined for non-compliance, regardless of their length of stay in the country. An exception is low-income immigrants whose behavior is not significantly different from that of natives. Immigrants are also less likely to actively participate in the tax declaration process (through the filing of deductions etc.), but most of this gap closes over time.

The general purpose of our analysis is to highlight the effects of tax complexity in ethnically diverse populations, revealing factors that policymakers need to take into account when assessing the efficiency and equity properties of the tax system. However, the differences in take-up that we document also have important implications for the spatial patterns in urban labor markets. For example, in the context of our commuting deduction analysis, the lower take-up of commuting deductions among immigrants is likely to affect the geographic scope of the area in which they search for work (see e.g., Le Gallo et al. 2017), with implications for residential patterns, the formation of ethnic enclaves, urban sprawl and the quality of employer-employee matching. Moreover, the bunching evidence tells us that knowledge about how to engage in (legal) tax planning and tax minimization is very different for natives and immigrants, and suggests that those who reside in areas with a high concentration of immigrants suffer the greatest informational disadvantage. This has implications for the decision to become self-employed, and ultimately affects the economic mobility and integration of immigrants. More generally, our results suggest that the spatial allocation of immigrants can have important implications for occupational choices by affecting the diffusion of knowledge about the incentives inherent in the tax system.

\footnotetext{
2 Commuting deductions are common in Western European countries, including the Nordic countries, Germany, Austria, Belgium, Luxembourg, France, the Netherlands, Switzerland, but do not exist in important economies outside Europe such as the US, Canada, UK and China (see, e.g., Potter et al., 2006; Paetzold and Winner, 2016).

${ }^{3}$ For example, if commuting by car, the time saving must be at least two hours per working day relative to using public transport. Notice that the deduction implies that the commuting cost (exceeding the threshold) is subsidized at a rate which depends on the individual's personal marginal tax rate.
}

Our paper contributes to the very active research literature on how individuals respond to tax complexity and the monetary incentives inherent in the tax system. This literature, which is surveyed in detail below, is increasingly highlighting that taxpayers do not perfectly optimize their behavior in relation to the tax system. However, there is not much empirical evidence showing which groups of the population are most likely characterized by such imperfect optimization and whether the effects are quantitatively significant. In this paper, we seek to fill this gap. Tax rules that are attractive on theoretical grounds might not work in practice if certain groups of taxpayers fail to respond to the implied incentives or if there are compliance and take-up costs that the policymaker did not anticipate.

The paper is organized as follows. In the next section, we survey the related literature. In Sections 3 and 4 we look separately at the two examples of the commuting deduction and the bunching at the kink of self-employed. Section 5 presents additional results on tax compliance behavior. Finally, we provide concluding remarks. The Appendices A-C provide additional information and empirical results.

\section{Related literature}

Our first empirical example looks at the Swedish commuting deduction. To the best of our knowledge, there is not much work on deduction behavior in general, and commuting deductions in particular. The reason for this is most likely the need for large and detailed administrative data sets. Two exceptions are Paetzold and Winner (2016) and Frimmel et al. (2018), who study commuting and other deductions from a different angle than ours, focusing on the tax evasion aspect. There is however a large related literature that looks at the take-up of various social benefits. Bargain et al. (2012) show for Finnish data that 40$50 \%$ of eligible individuals do not claim social benefits. Bhargava and Manoli (2015) state that the typical EITC non-claimant forgoes an estimated $\$ 1096 .{ }^{4}$ In comparison to this literature, we examine tax filing behavior and focus on higher income groups of the population.

The commuting deduction analysis relates to the urban economics literature that has examined the effects of commuting costs on a range of different outcomes. For example, Black et al. (2014) emphasize that commuting distance, and related costs, have a disproportionate negative effect on female labor force participation. Le Gallo et al. (2017) show in a large controlled experiment in France that reduced commuting costs have a positive effect on the job search activity of younger individuals. Hensen et al. (2009) establish that enhanced geographic mobility positively affects the quality of education-job matches using data from the Netherlands. Gutiérrez-i Puigarnau and van Ommeren (2010) show using German data that those with longer commutes have higher labor supply, arguing that this is a plausible outcome when workers have the option to vary both the number of hours worked per day and the number of workdays. ${ }^{5}$ More broadly, there is a large literature studying the effects of spatial aspects such as agglomeration and the quality and availability of transport infrastructure, on outcomes such as the geographical pattern of suburbanization, commuting behavior, employment and house prices (see, e.g., De la Roca 2017, Baum-Snow and Kahn 2000, Rosenthal and Strange 2008, Garcia-López 2012, Garcia-López et al. 2015; Mayer and Trevien 2017). There is also a literature on spatial mismatch which argues that geographical distance is a barrier to accessing available jobs. This mechanism is thought to especially affect ethnic minorities (see, e.g., Gabriel and Rosenthal 1996, Boustan and Margo 2009, Zenou 2013). The heterogeneity in the take-up of commuting deductions between different ethnic groups that we document

\footnotetext{
4 The literature provides several explanations for the lack of take-up, such as insufficient awareness (Chetty and Saez 2013) and the way information is presented (Saez 2009). The literature has also emphasized the importance of social image concerns, such as stigma costs (e.g., Friedrichsen et al. 2018).

5 See also Paetzold (2019a) who finds a positive relationship between the generosity of commuting subsidies and commuting distance.
} 
also adds a new angle to studies of the distributional effects of commuter subsidies (see Heuermann et al. 2017 for a recent contribution).

Our second empirical example, the bunching analysis, highlights the role of ethnic segregation in explaining how the self-employed react to the incentives in the tax system. It therefore relates to a branch of the literature studying the role of social interaction for economic behavior, emphasizing information transmission, spatial interactions and spill-over effects, and is connected to a research agenda examining spatial aspects of entrepreneurship (see Glaeser et al. 2010). ${ }^{6}$ Chetty et al. (2013) use "sharp" bunching behavior among the selfemployed as a proxy for local knowledge about tax rules and find that individuals who move from low to high bunching regions appear to optimize better after they move (in the sense of reporting incomes that to a greater extent maximize their EITC refund). Bezin and Moizeau (2017) study the relationship between cultural dynamics, urban segregation and inequality and discuss the costs and benefits of living in ethnically segregated areas. Drago et al. (2019) show by example of the Austrian TV license fee that information about letters to potential evaders spread and raise compliance within neighborhood networks in Austria. Also using Austrian data, in the context of commuting deductions, Paetzold and Winner (2016) find that tax evasion behavior changes when people move between workplaces, indicating the importance of the workplace as a domain of information transmission, and Frimmel et al. (2018) provide evidence of the inter-generational spillover of tax evasion behavior. ${ }^{7}$

Both our empirical examples relate to the literature analyzing the effects of complexity and salience of tax rules on taxpayer behavior. These issues have recently been analyzed from theoretical and empirical perspectives by Chetty et al. (2009), Abeler and Jäger (2015), Taubinsky and Rees-Jones (2018), and Blumkin et al. (2019). The literature generally supports the idea that taxpayers respond to tax incentives, but there is an increasing awareness of the need for refined theories in order to explain observed behavior. ${ }^{8}$ Hoopes et al. (2015) analyze taxpayers' search for information (using phone calls to the IRS and internet search data) and show that they actively get informed in order to comply with tax law. However, there is also the possibility of widespread misunderstanding of tax legislation, as highlighted by Feldman et al. (2016).

\footnotetext{
${ }^{6}$ The bunching analysis also relates to the rapidly growing literature that uses bunching evidence to measure behavioral responses. See Saez (2010), Chetty et al. (2011), and Bastani and Selin (2014). Many bunching studies focus, in similarity to our study, on the self-employed as the self-employed can more easily adjust their income through tax filing or labor supply adjustment as compared to wage-earners. They are also less constrained by third-party reporting, work hours constraints and have better access to professional tax planning. Indeed, the behavior of these groups have been shown to be very different from that of wage earners (Bastani and Selin 2014, Paetzold 2019b). Some studies document 'neoclassical' responses to monetary bunching incentives (e.g., Buhlmann et al. 2018, Doerrenberg et al. 2017, Paetzold 2019b), while other studies document behavior that does not conform with standard models. For example, Engström et al. (2015) and Engström et al. (2018) show that the decision to file for deductions causally depends on whether taxpayers have an initial deficit or credit with the tax authority, indicating the importance of loss aversion.

7 Other papers are Bohne and Nimczik (2018), who document information spread through the labor mobility of managers and tax experts, Alstadsæter et al. (2018) who show how tax avoidance spreads within family networks, and Alstadsæter and Jacob (2017) who document how information about tax avoidance opportunities spreads in local communities. In the context of welfare programs, Bertrand et al. (2000) examine social network effects in welfare take-up. They find that interacting with people who speak one's own language increases welfare take-up in local networks with high welfare take-up. See also Hansen and Lofstrom (2003) for an important early contribution on the welfare take-up among immigrants in Sweden.

${ }^{8}$ See Bernheim and Taubinsky (2018) for an overview of the emerging field of behavioral public economics. Behavioral biases that are mentioned in the literature include inattention (e.g., Hoopes et al. 2015), self-control problems and incorrect beliefs (Allcott et al. 2019), and present bias (Lockwood 2017).
}

Benzarti (2017) shows that taxpayers rationally forgo tax savings in order to save on compliance costs, and that such behavior is more prevalent among high-income earners, consistent with the idea that they have higher opportunity costs of time. Moreover, Aghion et al. (2018) examine how French self-employed respond to tax complexity and discuss the determinants of taxpayer learning, finding that individuals value simplicity, leave money on the table, learn over time and that complexity costs are more likely to affect individuals who are less educated or have lower income. ${ }^{9}$

A relevant question in our setting is what can be done to mitigate low take-up in the population, and there are some papers that have studied to which extent compliance frictions can be remedied by tax authorities. Mascagni (2018) is a recent survey on tax experiments, documenting a range of measures that have been tested for their effectiveness in raising compliance. ${ }^{10}$ Bhargava and Manoli (2015) report that complexity, salience and accuracy of beliefs can be successfully changed through intervention, whereas perceived stigma costs seem harder to affect. They also cite language barriers as a reason for lower take-up, which is related to the focus of our study. Guyton et al. (2016) and Manoli and Turner (2014) show that sending reminders can affect EITC take-up, especially among low-income filers. However, repeated reminders may be necessary for long-term effects. At the same time, Chetty and Saez (2013) caution that information provision alone might not be sufficient to have a significant average effect in the total population. Finally, Ramnath and Tong (2017) show that temporary policies (a one-time stimulus payment) can induce first-time tax filing with beneficial long-term effects for taxpayers, including continued tax filing and higher wages.

\section{Case 1: The commuting deduction}

In our first empirical example we analyze how natives and immigrants respond differently to the tax system in terms of filing for commuting deductions. Commuting deductions are standard elements in the tax systems of many European countries (such as the Nordic countries, Germany and France) but notably do not exist in countries such as the US, Canada and the UK. The purpose of commuting deductions is to compensate individuals for their different costs of earning income related to their expenses for traveling between their home and workplace. One important purpose of the commuting deduction is to incentivize individuals to search for and accept employment in a larger geographical area, thereby increasing labor market efficiency and positively impacting an individual's career and earnings prospects. However, as such deductions require the taxpayer to actively inform the tax authority about their travel expenses, this will create heterogeneous take-up in the population, which has distributional and fairness consequences. In particular, it can create unmotivated differences in tax burden between less informed groups of the population and more informed groups of the population.

\footnotetext{
9 Edmark and Gordon (2013) present evidence showing that high-income households respond to their relatively stronger incentives to incorporate their business. There is also a large related literature on tax morale, tax compliance and tax evasion. Allingham and Sandmo (1972) provided an early framework for thinking about tax evasion as a rational decision and the literature is surveyed by Slemrod (2007). The role of tax morale is analyzed in-depth by Luttmer and Singhal 2014. Recent papers using Scandinavian data are Engström and Holmlund (2009) who show that unincorporated self-employed who face less public scrutiny tend to under-report income to a larger extent than incorporated selfemployed individuals in Sweden, and Kleven et al. 2011 who find that cheating on self-reported income components in Denmark is widespread and that threatof-audit letters have significant effects on the reporting of these income components.

10 See also Robles (2009) and Fjeldstad and Heggstad (2012) who discuss, respectively, tax education policies in US states with high immigrant concentration, and in African countries that try to build a taxpayer culture.
} 


\section{(2) Avdrag - Tjänst}

\begin{tabular}{|l|l|}
\hline $\begin{array}{l}\text { 2.1 Resor till och från arbetet } \\
\text { Du får avdrag endast för den del som } \\
\text { överstiger } 10 \text { 000 kr. Fyll i totalbeloppet. }\end{array}$ & \\
\hline & \\
\hline
\end{tabular}

Fig. 1. The commuting deduction in the Swedish tax declaration form (illustration).

\subsection{Details on the commuting deduction}

As part of their annual tax declaration, Swedish income earners have the option of declaring their previous year's commuting cost. This can be done online or on paper. ${ }^{11}$ This declaration results in an automatic reduction of income tax for an amount that is a function of the part of the commuting cost that strictly exceeds the respective year's eligibility threshold. The threshold was SEK 7k in 2002-06, SEK 8k in 2007-08, SEK 9k in 2009-11, and SEK 10k in 2012-13. Notice that the deduction results in a reduction of taxable income for the amount exceeding the threshold, and therefore implies an effective subsidy to commuting costs with a rate depending on an individual's personal marginal income tax rate. The commuting deduction is the most common tax deduction in Sweden (Skatteverket 2018).

The tax declaration form contains a field for the deduction, see Fig. 1. The instructions on the left can be translated as "Travel to and from work. You receive a deduction only for the part exceeding SEK 10000. Fill in the total amount." Taxpayers do not have to take any action if they do not want to declare a commuting cost. In particular, they do not have to explicitly file a 'zero' commuting cost. Whenever a taxpayer does not exercise the option of declaring a commuting cost, this shows up as zero commuting cost in the data. Thus, when we discuss 'zero filing' below, this should be understood as 'no action has been taken' by the taxpayer regarding the commuting deduction. In the tax declaration, it is feasible to declare a commuting cost that is lower than the eligibility threshold. This has no apparent benefit for the taxpayer, and we refer to this as filing 'in the dominated region'.

The Swedish popular press regularly informs about tax deduction rules and common mistakes. According to a recent article (Aftonbladet.se 2018), there is widespread ignorance of the eligibility criteria among Swedish taxpayers. The tax authority in its press releases attempts to highlight the rules as well. From 2018, the tax authority provides an online tool that helps determine eligibility for the commuting deduction (Skatteverket 2018). According to the tax authority, nearly one million Swedish taxpayers declare commuting deductions, but about half of those taxpayers make some form of mistake or are not eligible at all. The most common mistake is to declare cost of commuting by car without fulfilling the eligibility criterion of a minimum two-hour time saving (per round trip) vis-a-vis public transport (Skatteverket 2018). ${ }^{12}$ An additional eligibility criteria is that the distance between home and work must be sufficiently large, and deductions for expenses using public transport are only granted for the cheapest mode of transportation (hence, it is not possible to reach eligibility threshold by e.g. purchasing first class train tickets). ${ }^{13}$

\footnotetext{
11 In contrast to many other countries, Swedish taxpayers do not usually use specialized software to prepare their tax declaration. Such software would typically alert them to potential deductions and eligibility criteria.

12 Taxpayers are required to save their receipts and the tax agency regularly performs audits on a subset of tax filers, requiring them to submit supporting documentation to the tax authority (such as receipts). The exact nature of these audits is not known, since details about auditing procedures are not typically conveyed by tax authorities to the public.

13 The minimum distance requirement is always satisfied in our empirical examples.
}

In this paper, we focus on commuters between the Stockholm and Uppsala municipalities. ${ }^{14}$ We do this for two reasons. First, this commuting region comprises one of the largest commuting flows in Sweden. Stockholm is Sweden's largest and Uppsala its fourth-largest city. Second, the geographical distance of about $70 \mathrm{~km}$ between these municipalities ensures eligibility for the commuting deduction if the commuter uses public transportation. The commuter trains between Stockholm and Uppsala are very well-developed. A single journey from Uppsala center to Stockholm city center takes between 30 and 50 minutes, depending on train operator and departure. If we take 2018 as a recent illustrative example, the eligibility threshold for the commuting deduction was a total commuting cost of SEK 11,000 ( $\approx 1100$ USD) and a round journey by train between Uppsala and Stockholm cost around SEK 250. A 30-day discounted ticket cost around SEK 1700 in 2018. Thus, a commuter would reach eligibility after 45 round trips under the single journey ticket or after 7 months under the 30-day ticket. ${ }^{15}$

\subsection{Data}

We use population-wide register data from Statistics Sweden covering the years 2002-13. ${ }^{16}$ The data allows us to identify individuals' municipalities of residence and their workplace location. The workplace information identifies the actual physical place of work (rather than the head office of the firm). We define an individual as a commuter if the municipalities of residence and workplace differ, and identify people who live in Uppsala and work in Stockholm or the other way round. This population data is linked with individuals' tax records. These contain the individuals' self-reported amount of commuting cost that has been declared in a given year's tax declaration. In this paper, we define an individual as taking up the commuting deduction if the self-reported traveling cost is (strictly) above the official threshold of the tax authority (Skatteverket) for the given tax year.

We restrict the sample to the working age population between age 20 and 64. Furthermore, to focus on individuals with a strong attachment to the labor market, we restrict ourselves to individuals who have an annual wage income above SEK 150k (in 2013 prices). ${ }^{17}$

We define natives as those born in Sweden and immigrants as all foreign-born individuals in the sample. The final sample contains 68 707 observations for natives and 9152 for immigrants. The register data contains information about immigrants' birth region (not birth country) and their year of arrival in Sweden. Based on the available birth region data, we classify immigrants as either Non-European immigrants, European immigrants (excluding the Nordic countries) or Nordic immigrants. ${ }^{18}$ Based on the information about year of arrival, we group

\footnotetext{
14 In the Tables A14 and A15 of Appendix A, we provide results for two other major commuting regions (Södertälje-Stockolm and Kungsbacka-Gothenburg) that are, however, geographically more compact and hence eligibility for the commuting deduction is less convincing that in our major example. The results are in line with the findings for the Stockholm-Uppsala region.

15 It is also possible to travel to and from work by car and deduct the associated expenses. However, as already mentioned, here an additional eligibility rule applies requiring the commuter to save at least two hours of commuting time relative to public transportation. In our empirical application, very few individuals would be eligible for deductions for this mode of travel.

16 The occupation data is available for this period only.

17 We have studied the sensitivity of our regression results with respect to the specification of this threshold, and the results appear robust. The corresponding regression results are shown in Tables A4 and A5 in Appendix A. Moreover, the workplace information is based on November data. It is conceivable that people switch jobs or workplaces within a year which can affect the eligibility for the commuting deduction. To address this issue, we show in Table A3 in Appendix A the regression results only for those commuters who work in the same workplace for two consecutive years.

18 Due to restrictions imposed by Statistics Sweden, the relatively small group of immigrants from the US, Canada and Oceania countries are all classified as Western European immigrants, and, thus, are included in our group of European
} 
Table 1

The composition of immigrants in the sample.

\begin{tabular}{lllll}
\hline & $\begin{array}{l}\text { All immigrants } \\
\text { percent }\end{array}$ & $\begin{array}{l}\text { Nordic } \\
\text { percent }\end{array}$ & $\begin{array}{l}\text { European } \\
\text { percent }\end{array}$ & $\begin{array}{l}\text { Non-European } \\
\text { percent }\end{array}$ \\
\hline Length of stay $\leq 5$ years & 13.92 & 11.31 & 20.21 & 9.77 \\
Length of stay 5-10 years & 12.27 & 10.12 & 16.95 & 9.26 \\
Length of stay > 10 years & 73.81 & 78.57 & 62.85 & 80.97 \\
Observations & 9152 & 1591 & 3405 & 4156 \\
\hline
\end{tabular}

Table 2

The average age in different population groups.

\begin{tabular}{lllll}
\hline & All immigrants & Nordic & European & Non-European \\
\hline Length of stay $\leq 5$ yrs & 34.38 & 34.14 & 34.43 & 34.40 \\
& $(7.78)$ & $(7.44)$ & $(7.27)$ & $(8.72)$ \\
Length of stay $5-10$ yrs & 37.56 & 35.52 & 37.92 & 37.88 \\
& $(7.85)$ & $(7.59)$ & $(7.08)$ & $(8.87)$ \\
Length of stay $>10$ yrs & 43.32 & 48.08 & 45.19 & 40.33 \\
& $(10.86)$ & $(9.62)$ & $(10.43)$ & $(10.67)$ \\
Observations & 9152 & 1591 & 3405 & 4156 \\
\hline
\end{tabular}

Standard deviation in parentheses.

Table 3

The occupation distribution among commuters

\begin{tabular}{lll}
\hline & $\begin{array}{l}\text { Native commuters } \\
\text { Percent }\end{array}$ & $\begin{array}{l}\text { Immigrant commuters } \\
\text { Percent }\end{array}$ \\
\hline $\begin{array}{l}\text { Legislators, senior officials and } \\
\quad \text { managers }\end{array}$ & 11.46 & 6.55 \\
$\quad \begin{array}{l}\text { Professionals } \\
\text { Technicians and associate }\end{array}$ & 49.91 & 50.48 \\
$\quad$ professionals & 22.31 & 20.09 \\
$\quad \begin{array}{l}\text { Clerks } \\
\text { Service workers and shop sales }\end{array}$ & 5.26 & 5.79 \\
$\quad$ workers & 5.25 & 8.45 \\
$\quad$ Skilled agricultural and fishery & 0.09 & 0.08 \\
$\quad$ workers & 3.05 & 3.25 \\
$\quad$ Craft and related trade workers & 1.64 & 1.99 \\
$\quad$ Plant and machine operators and & & \\
$\quad$ assemblers & 1.03 & 3.33 \\
$\quad$ Elementary occupations & 100.00 & 100.00 \\
$\quad$ Total & & \\
\hline
\end{tabular}

each immigrant into one of three groups for each data year: arrived in Sweden less than 5 years ago, between 5 and 10 years ago, and more than 10 years ago. Furthermore, by interacting the region of birth with the time since arrival in the host country, we create 9 immigrant-cohort groups, as shown in Table 1 . The majority of immigrant commuters have stayed in Sweden for more than 10 years, comprising about $74 \%$ of immigrant observations. In contrast, only about $14 \%$ of immigrants have been residing in Sweden for less than 5 years.

In Table 2 we show the age composition of native and immigrant commuters depending on their length of stay in the host country. We see that there are few age differences between immigrants with different origin, but immigrants who are more recently arrived tend to be younger.

Table 3 shows the occupation distribution. As we can see, most of the native and immigrant commuters are working in highly skilled occupations.

Table 4 provides summary statistics for the main outcome variable and our control variables. The binary outcome variable Deduction in

immigrants. We have also looked at an alternative geographical classifications based on the similarity of the respective countries' taxation systems, in which we classify immigrants as either Nordic immigrants, Western European immigrants or 'other' immigrants. The corresponding results are shown in Tables A7-A11 in Appendix A. The results suggest that recently arrived non-Nordic immigrants are less likely than natives to take up the deduction. Furthermore, recently arrived Nordic and Western European immigrants are more likely than natives to file in the dominated region.
Table 4

Summary statistics for the outcome and control variables.

\begin{tabular}{llllll}
\hline & \multicolumn{2}{l}{ Native commuters } & & \multicolumn{2}{l}{ Immigrant commuters } \\
& Mean & SD & & Mean & SD \\
\hline Deduction & 0.64 & 0.48 & & 0.63 & 0.48 \\
Age & 41.16 & 11.19 & & 41.36 & 10.70 \\
Married & 0.43 & 0.50 & & 0.50 & 0.50 \\
Primary School & 0.03 & 0.18 & & 0.03 & 0.18 \\
Secondary School & 0.22 & 0.41 & & 0.20 & 0.40 \\
University & 0.75 & 0.43 & & 0.77 & 0.42 \\
Female & 0.35 & 0.48 & & 0.39 & 0.49 \\
Earned taxable labor income & 487.56 & 396.49 & & 420.10 & 245.16 \\
$\quad$ SEK 1k) & 0.80 & 0.41 & & 0.74 & 0.44 \\
Uppsala & & & & &
\end{tabular}

Table 4 measures whether the filed cost is strictly above the eligibility threshold or not. On average, $64 \%$ of commuters file some amount of commuting cost above the threshold and the mean value is very similar between native and immigrant commuters. However, as we will see below, these figures contain interesting heterogeneity. Importantly, as evident from Table 4, natives and immigrants in the sample are very similar in terms of background characteristics and the majority of commuters in the sample are highly educated. The share of university-educated commuters is about 75 , resp. $77 \%$ for natives, resp. immigrants. The share of female commuters is 35 , resp. $39 \%$ among natives, resp. immigrants. They also tend to have a similar regional commuting pattern. As indicated by the dummy variable Uppsala, about 80 and $74 \%$ of natives and immigrants, respectively, are living in Uppsala and commute to Stockholm. The remaining commuters travel in the other direction. The only noteworthy difference is that native commuters have higher taxable earnings than immigrant commuters.

In the sample, 50782 natives (74\%) and 6653 immigrants (73\%) file a strictly positive commuting cost. Fig. 2 shows the distribution of declared commuting cost by native and immigrant commuters. It contains four panels, one for each of the four periods in which the threshold was constant (as mentioned in Section 3.1, the threshold was SEK 7k 200206, SEK 8k 2007-08, SEK 9k 2009-11, and SEK 10k 2012-13). We find that a substantial fraction of commuters declare commuting costs in the 'dominated region', i.e., above zero but below the eligibility threshold. However, most of the non-zero declarations are above the threshold. The majority of the filed costs fall in the interval above the threshold and below SEK 50k. There are some outliers who file very large amounts, but we are not able to verify whether these are mistakes or represent cheating. ${ }^{19}$

Finally, we show a descriptive graph showing the average take-up depending on age, ethnicity and duration of stay in the host country (see Fig. 3). Here we see that there is a clear age gradient in the take-up for natives and immigrants who have stayed in the host country for a long time, but less so for more recently arrived immigrants.

\subsection{Results}

We now go beyond the purely descriptive analysis and run multivariate regressions where we can control for a rich set of covariates, enabling us to compare the take-up behavior of immigrants and natives who are identical along several dimensions. A key aspect of our approach is that we focus on a commuting zone where the public infrastructure is so well-developed, making public transportation the natural choice for the vast majority of commuters, rendering concerns about unobserved differences between ethnic groups in the taste or costs for different modes of transportation less relevant. Moreover, full-time com-

\footnotetext{
19 Notice that, unless there is an audit, the filed amount is accepted by the tax authority. Our results are robust to excluding individuals with claimed deductions of more than SEK 50k.
} 

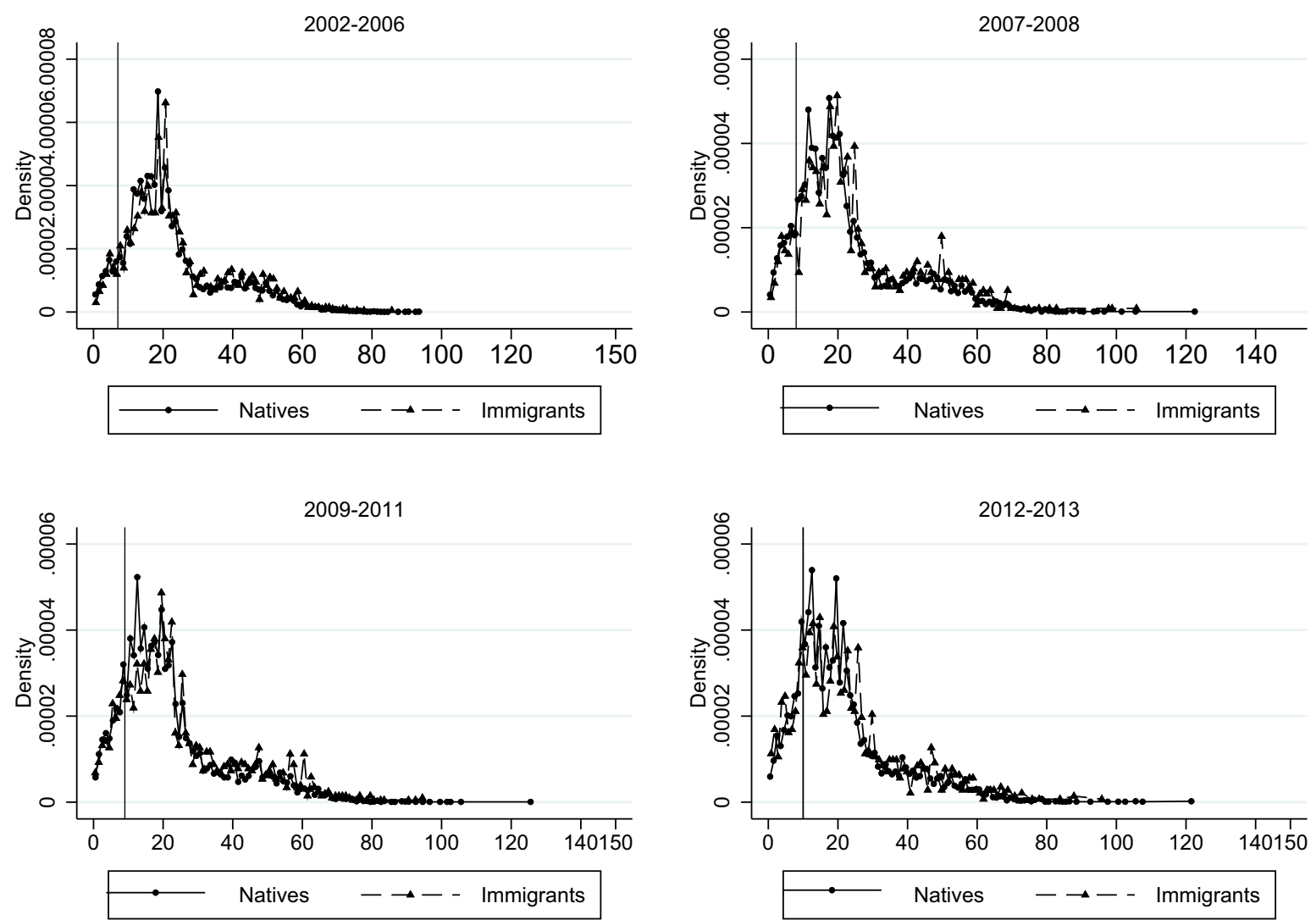

Fig. 2. The distribution of declared commuting cost (in SEK 1000) across native and immigrant commuters (deduction threshold marked by a vertical line).
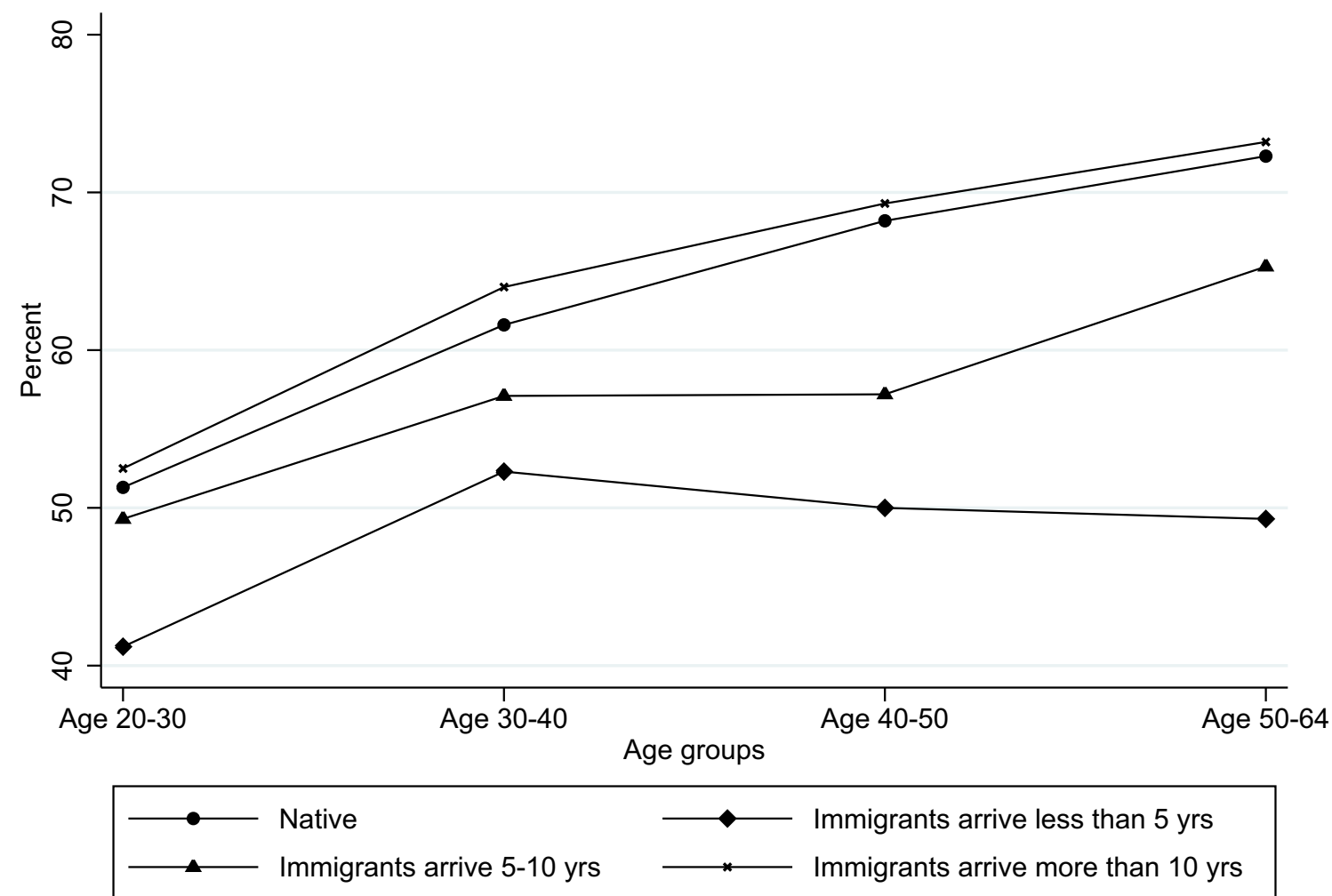

Fig. 3. The average take-up of the commuting deduction based on ethnicity, age, and length of stay in the host country (raw averages). 

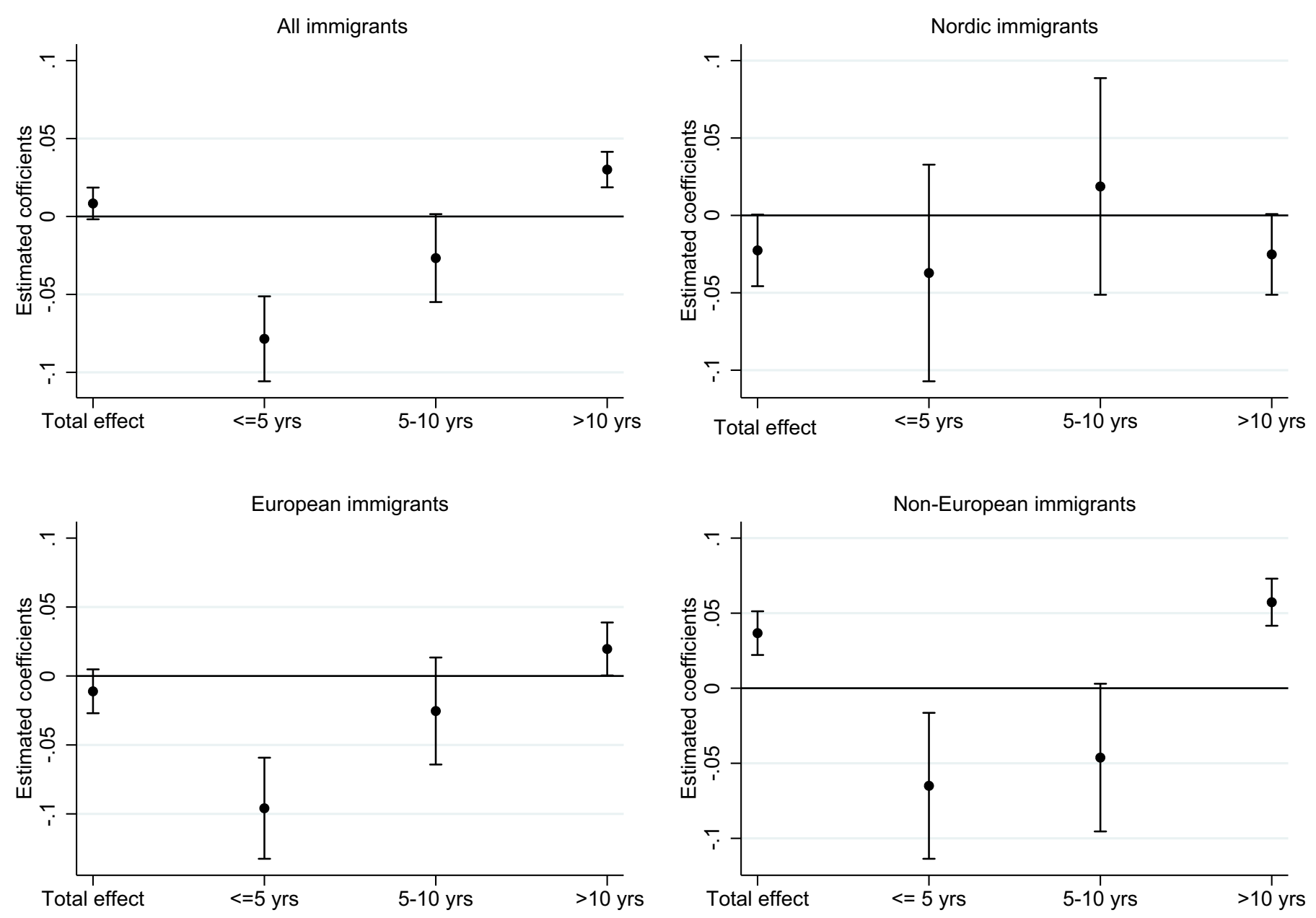

Fig. 4. The probability of taking up the commuting deduction by birth region and length of stay.

muters using public transportation are guaranteed to be eligible for the commuting deduction.

In our regressions, we use native commuters as the reference group. We employ a linear probability model to estimate the probability of taking up the commuting deduction. Our regression model is

$D_{i j t}=\alpha+\beta$ Imm $_{i}+X_{i t}^{\prime} \gamma+$ Occupation $_{i t}+\pi_{j}+\lambda_{t}+\epsilon_{i t}$,

where subscripts identify the commuter $(i)$, the residential municipality $(j)$ and the year $(t) . D_{i j t}$ is the binary outcome variable where the value 1 indicates take-up, i.e., that the self-reported commuting cost is (strictly) above the eligibility threshold in the respective year, while 0 means no take-up, i.e., the declared cost is zero or it is positive but does not exceed the threshold (dominated region). $\mathrm{Imm}_{i}$ equals 1 if the commuter is an immigrant and 0 otherwise. $X_{i t}$ is a set of control variables including age, gender, secondary school, university, marital status (whether married or not) and annual earned taxable labor income. ${ }^{20}$ The variable Occupation $_{i t}$ is a set of occupation dummies, corresponding to the categories listed in Table 3 . The dummy variable $\pi_{j}$ indicates whether the residential municipality is Uppsala or not and $\lambda_{t}$ controls for the year effect. Finally, $\epsilon_{i t}$ is an error term.

Fig. 4 shows the regression results for the commuters between Stockholm and Uppsala (Table A1 in Appendix A contains the results in table form). As we use native commuters as the reference group, the estimated

\footnotetext{
${ }^{20}$ We have also performed regressions where we control for income in a nonlinear way, and all our qualitative results remain the same. The results are shown in Table A6.
}

coefficients should be interpreted as the relative difference between immigrants and natives in terms of percentage points (positive coefficients indicate higher take-up of immigrants relative to natives). The upper left panel shows the results for all immigrants. In total, the probability of taking up the commuting deduction is on average similar between native and immigrant commuters (the estimated coefficient is slightly above zero but statistically insignificant). However, if we decompose immigrants by time since arrival, we find that immigrant commuters with fewer than five years of stay are significantly less likely to take up the deduction than natives, where the difference is about 7.8 percentage points. Over time, immigrants increase their take-up (the estimated coefficient becomes smaller in size and insignificant after five years of stay) and it becomes even larger than natives after more than ten years of stay (the coefficient is positive and significant). In Fig. 4 we also decompose the effect based on immigrants' region of origin. We find that the differences relative to natives are mainly driven by immigrants from European and non-European countries. Immigrants from Nordic countries behave more or less like natives, however, they make up only $17 \%$ of the immigrant commuters (see Table 1).

In our sample, more than $10 \%$ of commuters file a commuting cost in the 'dominated region', i.e. above zero but below the eligibility threshold, as Fig. 5 illustrates. ${ }^{21}$ We analyze this behavior in a regression in which the dependent variable equals 1 if the self-reported commuting

\footnotetext{
21 Similar to the evidence for Pakistan shown in Kleven and Waseem (2013), our filing in the dominated region is also an example of filing in a strictly dominated region that only has a cost and no benefit; and hence would not happen in a frictionless world.
} 
All immigrants

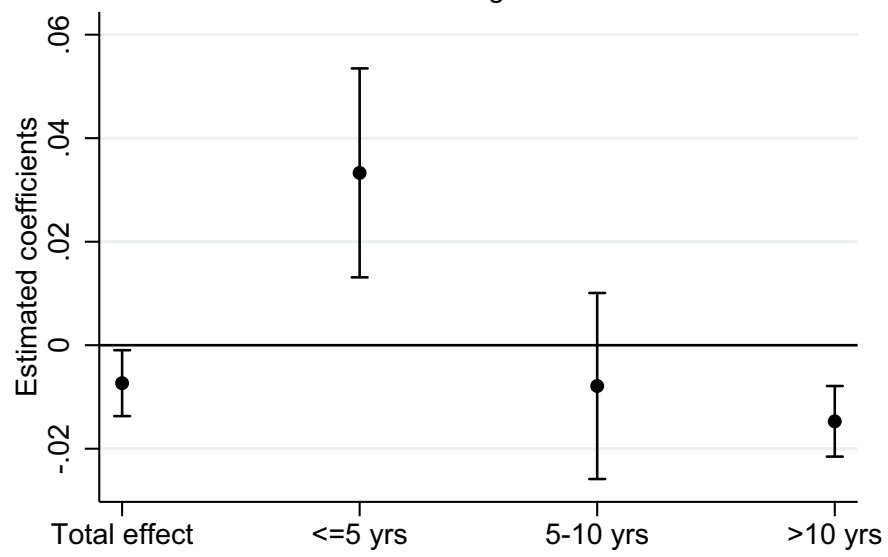

European immigrants

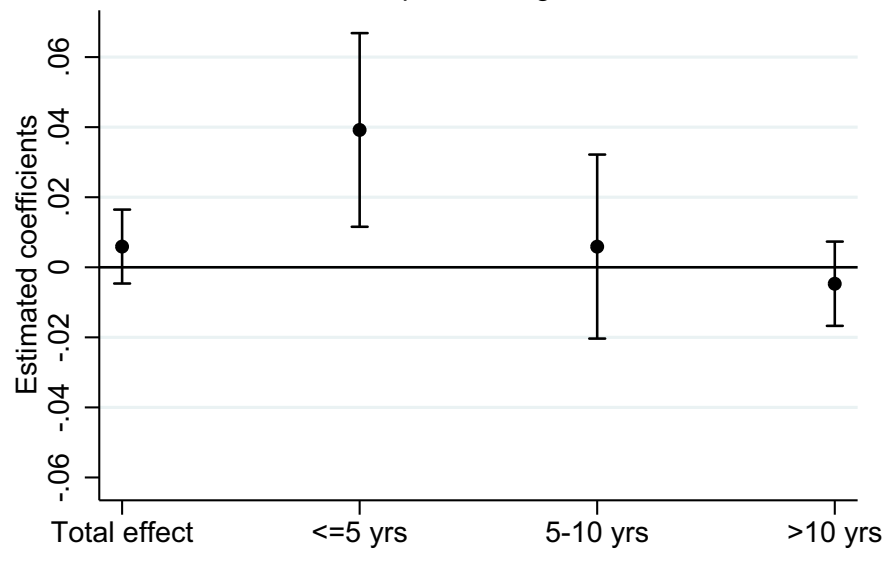

Nordic immigrants

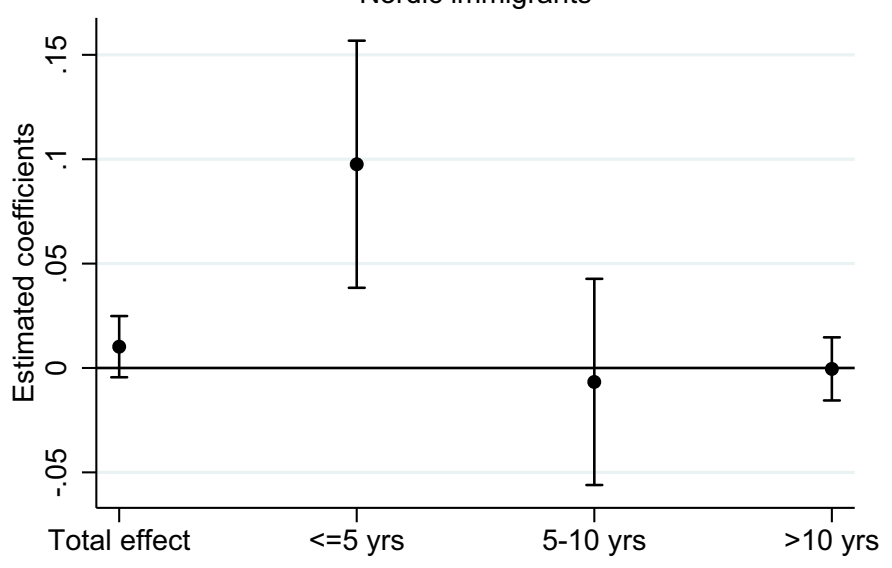

Fig. 5. The probability of filing a commuting cost in the dominated region.

deduction is in the dominated region (Table A2 in Appendix A contains the regression in table form). The dependent variable is 0 if the stated cost is either zero or above the threshold.

Similar to the previous results on the take-up of the commuting deduction, we see that the total population of immigrants is not very different from natives with respect to filing in the dominated region. However, as before, decomposing the immigrant population by length of stay reveals a clear pattern. Recently arrived immigrants from Nordic and European countries have significantly higher propensity to file in the dominated region than natives, perhaps because they expect such a deduction but are not fully informed about the rules. Moreover, immigrants appear to learn over time, and after more than 10 years, immigrants are clearly less likely than natives to file in the dominated region. Non-European immigrants are already after 5 years of stay less likely than natives to file in the dominated region. In contrast to European or Nordic immigrants, it might be that Non-Europeans are not "biased" in the sense that they are not expecting a commuting deduction and are therefore less likely to file in the dominated region. In other words, they are more likely either to not file the deduction at all (zeros) or to file a "correct" deduction above the threshold.

Appendix A contains supplementary material to this section. Tables A1-A6 present regression results based on the classification of birth region described above. Tables A7-A11 contain regression results based on an alternative classification of birth region. Table A12 presents extensive robustness checks with respect to occupation controls and more flexible age controls. Table A13 presents a formal analysis of heterogeneous take-up based on age, ethnicity and duration of stay in the host country, basically confirming the age gradient in take-up as evident from
Fig. 3. Finally, Tables A14 and A15 report results for two other commuting regions in Sweden.

\subsection{Discussion}

Our main interest is to identify relevant differences in tax filing behavior between natives and immigrants. We have found that in the context of the commuting expense deduction, that filing behavior of immigrant commuters as a whole is on average similar to that of natives. However, when differentiating immigrants by region of origin and length of stay in Sweden, striking differences emerge. Immigrants initially have a lower take-up than natives, but learn over time and after more than 10 years in the country they have an even higher takeup than natives and file less in the dominated region. One clear difference between European/Nordic immigrants and Non-Europeans is that the former initially file more in the dominated region than natives do. We conjecture that this difference is due to the fact that European and Nordic immigrants are on average more familiar with the concept of commuting deductions, but do not fully understand the eligibility criteria. This conjecture is supported by the results reported in Table A8 (Appendix A) from a regression that is based on an alternative classification of birth region, where we classify immigrants by the type of tax system in their home country. We see that Western European (and Nordic) immigrants, who are familiar with similar tax systems, file more in the dominated region than immigrants from other regions.

Around $16 \%$ of commuters in our sample (native and immigrants) do not file a commuting cost at all. This might have different explanations. 
For recently arrived immigrants, language barriers seem a convincing explanation, as the tax forms are sent out in Swedish. This conjecture is supported by the higher level of compliance of Nordic immigrants, and by the fact that immigrants catch up over time. A share of non-filers might commute by car and therefore might know that they are not eligible for deductions because they do not save two hours per round trip. There is also the possibility that individuals might be unaware of the deduction and eligibility criteria, or simply make a conscious decision not to file. Full compliance with the deduction rules requires collecting proof of one's commuting cost and adding up the expenditure. As a deduction is only granted for the amount exceeding the threshold, this might not be sufficiently attractive for everyone. Similarly, getting informed is costly, too. Moreover, in Sweden (as in other Nordic countries), a typical taxpayer's income is close to completely third-party reported and the tax authority advertises the possibility to receive an early tax return to those taxpayers who accept without changes the preliminary tax statement that is sent to them by the authority. This might discourage taxpayers from getting actively involved in information acquisition and deduction filing.

Before closing this section we would like to make three additional remarks regarding the interpretation of our estimates.

First, the literature has documented that there is a large amount of tax evasion and cheating regarding self-reported items on tax declarations (e.g., Paetzold and Winner 2016). The Swedish tax authority also reports substantial problems with incorrect or outright unjustified deductions (Skatteverket 2018). Our data allows us to highlight differences in tax filing behavior between natives and immigrants, which is the focus of this study. We are not able to identify cheating. However, by construction of our sample, we try to make sure that we identify eligible commuters with high probability.

Second, the sample of commuters is potentially selected since knowledge of the commuting deduction might influence residential and workplace location choices (i.e. the decision to become a commuter). This might lead us to understate the group differences since less informed taxpayers are less likely to become commuters and immigrants are more likely to be uninformed. However, we are not sure about the quantitative significance of this effect.

Third, although we have been able to control for a rich set of covariates in our analysis, we cannot rule out that there are unobserved differences between natives and immigrants regarding their preferred mode of transportation (car vs. public transport). We presume, however, that conditional on observable covariates, given our focus on individuals with relatively high incomes and high education and the well-developed public infrastructure in the Uppsala-Stockholm region, differences in preferences regarding car travel and public transportation between the two groups should not be too much of a concern. A widened explanation for our findings could be that as immigrants integrate into society, both their familiarity with public transport and their familiarity with tax rules increase, starting from a potentially lower level than natives. Our results in the second empirical example (bunching) that we turn to in the next section makes us, however, confident that knowledge about the tax system is the driving factor behind our findings.

\section{Case 2: Bunching estimates}

Economic theory predicts that if a population of individuals have different (smoothly distributed) preferences over pre-tax income and consumption due to different earnings capacities, there should be an excess mass of taxpayers at points of the tax schedule where marginal tax rates discontinuously increase. In a very influential paper, Saez (2010) showed that this mass is proportional to the taxable income elasticity, which is a key parameter used when assessing the distortionary costs of income taxation. Our second empirical example compares the tax filing behavior of self-employed natives and immigrants by estimating elasticities capturing behavioral responses to changes in marginal tax rates at the first kink point of the Swedish central government income tax. ${ }^{22}$

A key issue in the contemporary bunching literature is the question to which extent the bunching method is actually able to detect bunching responses if individuals cannot perfectly control their income level. For example, if individuals desire to locate at the kink point, but face a symmetric and normally distributed optimization error, then no bunching will be visible, provided the variance of the error component is sufficiently large. For this reason, the bunching results that have been most informative are those that relate to self-employed individuals (who by virtue of setting their own salaries have a greater flexibility to bunch at the kink) and for institutional settings with very large kinks (where the utility cost of not bunching at the kink also is large).

The major advantage of the Swedish tax kink is that it is very large (in recent years, an increase in the marginal tax rate of 20 percentage points) and located in the upper middle part of the income distribution where many taxpayers are located and the underlying income distribution is smooth and triangular shaped. ${ }^{23}$ Therefore, the Swedish kink point provides an excellent laboratory to examine differential responses in bunching behavior between native and immigrant groups of the population. Bastani and Selin (2014) demonstrated that self-employed individuals sharply bunch at the kink, although the sizes of the implied elasticities were not very large. In this paper, we are not interested in the absolute elasticity of taxable income for self-employed individuals, but rather in the difference in the elasticity between natives and immigrants. We use the kink as a very salient example of a tax incentive in our quest to understand differences in tax filing behavior between different groups of the population.

\subsection{Data}

For our bunching analysis, we use data on the universe of Swedish taxpayers from 2002 to 2015, focusing on self-employed individuals. ${ }^{24}$ The location of the first central governmental tax kink point differs across years. We convert the taxable income distribution and thresholds to 2015 prices and consider the working-age population between age 20 and 64 .

In bunching studies, the researcher typically specifies a 'small' and a 'wide' bunching window. The small bunching window determines the income observations around the kink point that should be excluded when fitting the counter-factual distribution (i.e. what the taxable income distribution would look like in the absence of a kink). The wide bunching window specifies how much data to the left and to the right of the small bunching window that is available for the estimation of the counter-factual distribution. The size of the large bunching window is of less importance provided one restricts the interval to regions of the income distribution that have the same shape and as long as one does not choose the window so large so as to include other kink points or discontinuities in the tax code that could contaminate the results.

Following Bastani and Selin (2014), we select a sample of selfemployed individuals with earned taxable income falling into a wide

\footnotetext{
22 This is the same kink point that was analyzed by Bastani and Selin (2014). In similarity to that paper, we use the refinement of Saez's bunching method developed by Chetty et al. (2011) who showed how one can estimate the excess mass at a kink point by estimating how the taxable income distribution would look like in the absence of a kink (the counter-factual distribution) by fitting a polynomial, excluding a certain interval around the kink.

${ }^{23}$ The identification assumption underlying the bunching method is that there should be no spike in the counter-factual distribution at the income level of the kink.

${ }^{24}$ In the population data, Statistics Sweden (SCB) defines a person as selfemployed in a given year, if that person's November income is mainly derived from self-employment activities. If a person has both wage and self-employment income and the self-employment income multiplied by 1.6 is greater than wage income in November, SCB will classify the person as self-employed.
} 

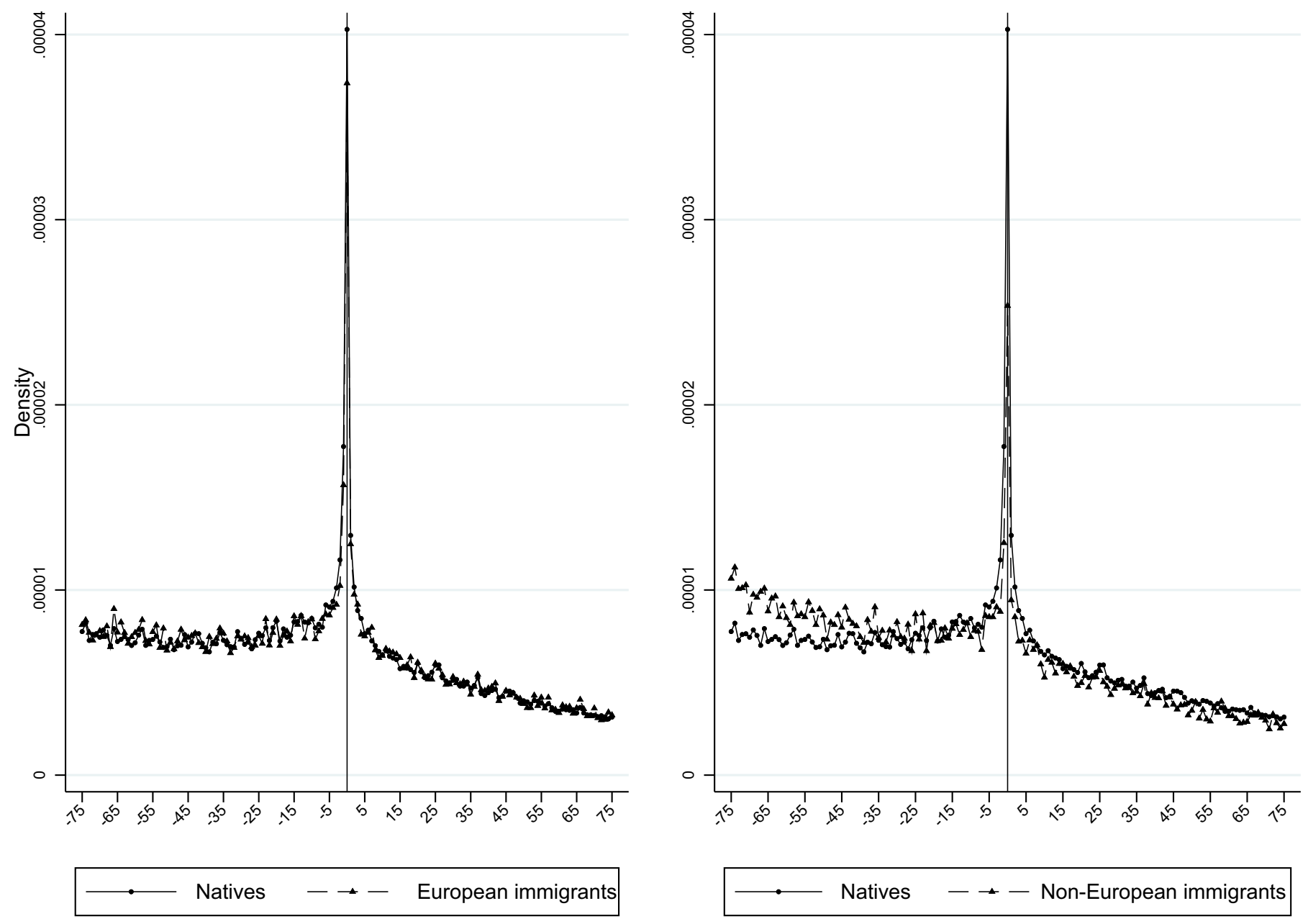

Fig. 6. Distance to the first kink point of the central government tax, 2002-15.

bunching window of SEK [-75k, 75k] around the first kink point of the central government tax in a given year. As before, we define immigrants as foreign-born. We further classify immigrants into European immigrants and non-European immigrants. ${ }^{25}$ Following the above definitions, the sample includes 1230926 self-employed natives and 123671 self-employed immigrants. Among self-employed immigrants, the number of immigrants from European countries and non-European countries are 78949 and 44 722, respectively. Panel A of Table B1 (Appendix B) contains summary statistics for the sample.

We calculate the distance between each individuals' taxable income and the first central governmental kink point. Fig. 6 shows the distribution of the distance to the kink for different groups of the population, where the vertical line indicates the location of the first central governmental kink point. The left panel compares the distributions for self-employed natives and European immigrants whereas the right panel shows the distributions for self-employed natives and non-European immigrants. In the left panel, we observe a sharp spike at the kink that is similar in magnitude for both natives and European immigrants and the two distributions appear quite similar. In the right panel, however, clear differences emerge. Notably, the spike is smaller for Non-European immigrants than for natives and the density to the left of the kink looks quite different.

25 The bunching estimation is data-intensive. Therefore, we include Nordic immigrants as a part of the European immigrants, different from our classification in the commuter deduction analysis. As before, European immigrants include immigrants from Canada, U.S. and Oceania countries.

\subsection{Results}

\subsubsection{Baseline results}

In our analysis, we fix the wide bunching window to SEK [ $-75 k, 75 k]$ and perform a sensitivity analysis with respect to the size of the small bunching window, choosing intervals between SEK $[-5 k, 5 k]$ and SEK $[-1 \mathrm{k}, 1 \mathrm{k}]$ around the kink point. We use different sets of small bunching windows because the selection of the small window is subjective. A too small (large) bunching window would underestimate (overestimate) the excess mass and the associated behavioral response. As our parametric fit of the counter-factual distribution we use a 7 th degree polynomial. ${ }^{26}$ All standard errors for the estimated excess mass are computed using a conventional bootstrap procedure. For each estimate of the excess mass at the kink, we compute the corresponding taxable income elasticity. ${ }^{27}$

The results are shown in Fig. 7. The upper panel of the figure displays taxable income elasticities for immigrants obtained through bunching estimation, expressed as a percentage of the corresponding native elasticities. The lower panel shows the differences between natives and immigrants in terms of the probability to locate in a given interval around

\footnotetext{
${ }^{26}$ Sensitivity checks using different bunching windows and polynomial orders are shown in Tables B3 and B4 in Appendix B, and the results are robust. The difference in excess mass between self-employed natives and European immigrants remains small, whereas the difference between self-employed natives and nonEuropean immigrants remains large.

27 For details on the computation of the taxable income elasticity, refer to the text in the beginning of Appendix B.
} 


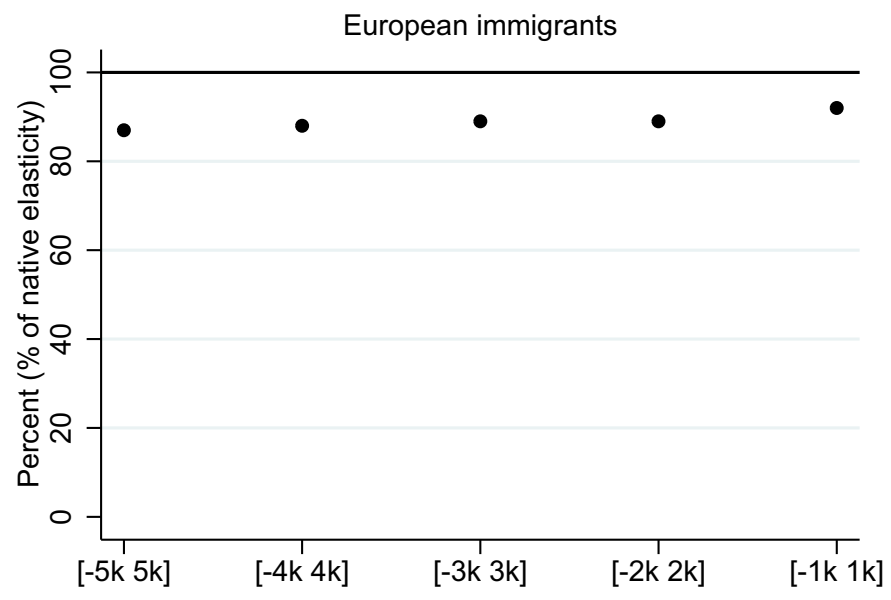

European immigrants

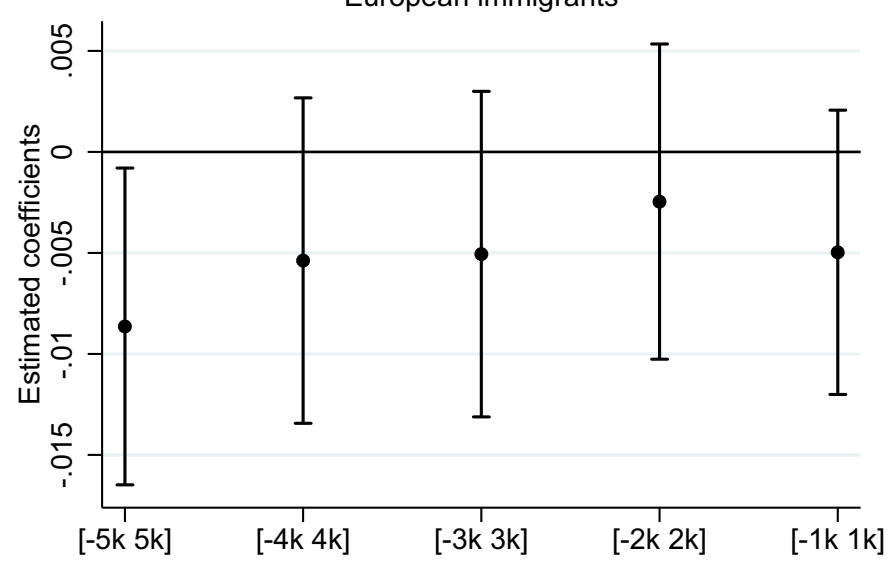

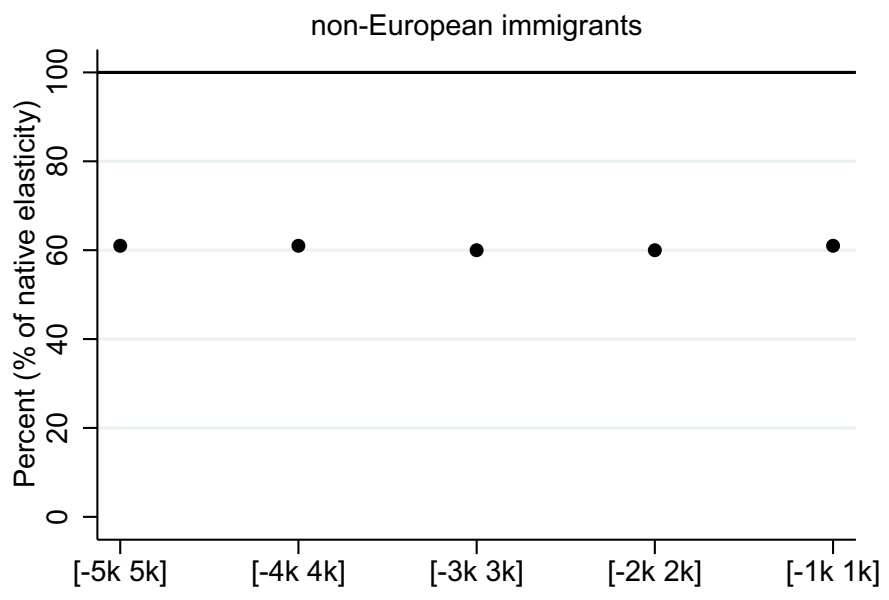

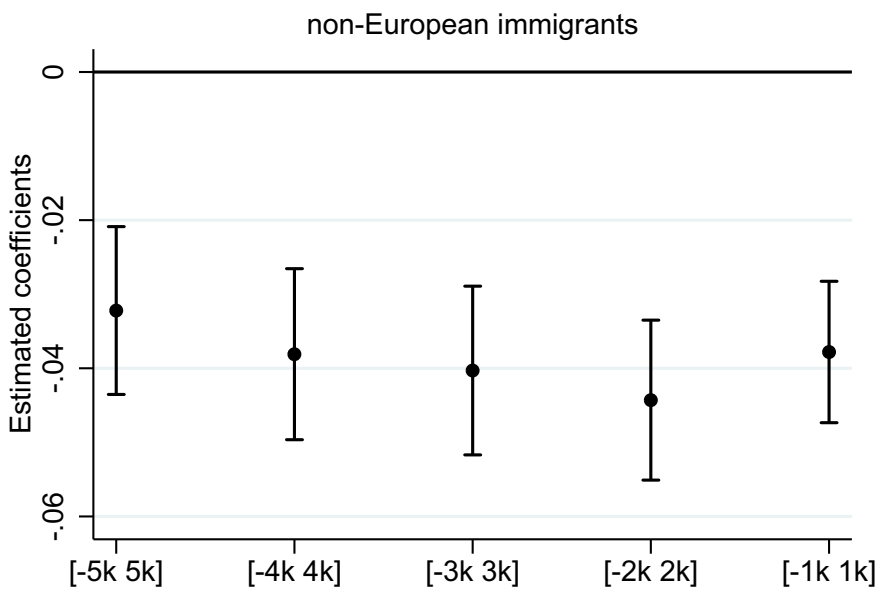

Fig. 7. Baseline bunching estimates and regression coefficients.

the kink, as measured by a multivariable regression controlling for background characteristics.

We begin by describing the upper panel which contains the bunching estimates. Looking at the results for the small bunching window $[-5 k$, $5 \mathrm{k}$, we see that the difference in taxable income elasticity between selfemployed natives and European immigrants is small. ${ }^{28}$ On average, the implied elasticity for self-employed European immigrants is around $90 \%$ of the native elasticity. In contrast, the elasticity for self-employed nonEuropean immigrants is only about $60 \%$ of the native elasticity (upper right panel of Fig. 7). Complementing Fig. 7, we present the corresponding graphical bunching analyses in Figure B1 (Appendix B) and the exact bunching estimates as well as the implied elasticities for each group in the upper half of Table B2 (Appendix B).

The bunching analysis highlights different bunching behavior between natives and, especially, non-European, immigrants. However, these differences might be due to differences in individual characteristics as well as due to regional differences. Therefore, we complement the bunching estimation with regressions where we are able to control for individual characteristics and municipal fixed effects. ${ }^{29}$

$\overline{28}$ Observe that the results are similar for the other "small" windows. Notice also that Table B2 (upper half, Appendix B) shows that the elasticity for selfemployed natives is about 0.041 .

${ }^{29}$ For this regression analysis, we restrict the sample to the wide window SEK $[-10 \mathrm{k}, 10 \mathrm{k}]$ around the central governmental tax point, which makes earnings ability among the self-employed more comparable. This sub-sample contains 265671 natives, 15827 European immigrants and 7729 non-European immigrants. In the restricted sample, 169643 natives, 9903 European immigrants and 4572 non-European immigrants have incomes that fall in the small bunch-
We focus on the following linear probability model:

$Y_{i j t}=\alpha+\beta$ Europe $_{i}+\gamma$ NonEurope $_{i}+X_{i t}^{\prime} \theta+\pi_{j}+\lambda_{t}+\epsilon_{i t}$

The subscripts $i, j$ and $t$ denote individual, municipality and year. The dependent binary variable $Y$ equals 1 if the taxable income is within the small bunching window and 0 otherwise. The dummy variables Europe and NonEurope indicate the region of origin of immigrants, with selfemployed natives as the reference group. The estimated coefficients $\beta$ and $\gamma$ measure to what extent the propensity of an immigrant's taxable income falling in the small bunching window differs from that of selfemployed natives. $X_{i t}$ is a set of control variables: age, female, secondary school, university and marital status. $\pi_{j}$ and $\lambda_{t}$ control for municipality and year fixed effects.

The regressions results are presented in graphical form in the lower half of Fig. 7 (see Table B2 in Appendix B for more detailed results). The estimated coefficients for self-employed European immigrants are quantitatively small and statistically insignificant, supporting the finding above that bunching among European immigrants is not very different from bunching among natives. In contrast, the coefficients for non-European immigrants vary from about -0.03 to about -0.04 as we shrink the small bunching window from $[-5 k, 5 k]$ to $[-1 k, 1 k]$ SEK, and all the estimates are statistically significant. The probability of a non-European immigrant to fall into the small bunching window of SEK [-5k, 5k] is about 3 percentage points lower than that of selfemployed natives. Altogether, the regression results are in line with the

ing window $[-5 k, 5 k]$. The summary statistics for this restricted sample are given in panel B of Table B1 (Appendix B). 
bunching estimation in the sense that they show that self-employed natives respond more to the kink than self-employed non-European immigrants, whereas European immigrants exhibit similar behavior as natives. ${ }^{30}$

Having presented the baseline bunching analysis, we now take a closer look at how the composition of our sample of self-employed immigrants affects the bunching results. We first look at ethnic segregation at the place of residence, followed by analyzing the role organizational form for the self-employed, i.e., whether their businesses are incorporated or not. For each case, we conduct a bunching estimation as well as regressions as described above.

We have also repeated the bunching analysis using taxable income before any deductions. The results do not differ much from the baseline results, indicating that self-employed people mainly use either labor supply or income planning to locate at the kink point rather than deductions. This is in line with Paetzold (2019b) who showed that deductions are not a major channel for income adjustment for self-employed in Austria.

In our commuting deduction analysis we considered immigrants' time since arrival in the host country to be an interesting dimension to study. This is also an interesting dimension to consider in the bunching analysis. However, the average length of stay for self-employed European and non-European immigrants is about 27 and 21 years respectively. Given that the bunching analysis is conducted in a high income region of the income distribution, sample size limitations precent us from investigating this issue here. ${ }^{31}$

\subsubsection{Residential segregation}

The advantages and disadvantages of living in an ethnic enclave have been discussed in the literature. ${ }^{32}$ On the one hand, an ethnic enclave may facilitate the transmission of information among immigrants. On the other hand, a more segregated area may hinder integration and access to information due to fewer interactions with natives and the society of the host country. An ethnic enclave can also exert 'pressure' through norms and (perceived) stigma cost. Therefore, tax filing behavior of immigrants living in an ethnic enclave may differ from that immigrants who live in less segregated areas.

In the data, we can identify individuals' residential location at parish level. A municipality in Sweden can include several parishes. According to Statistics Sweden, there are about 290 municipalities and about 1500 parishes in Sweden in 2011. In this section, we restrict attention to the years 2002-14 for which the parish data is available. Using the whole population data of Sweden, we calculate, for each parish, the share of European immigrants and the share of non-European immi-

\footnotetext{
${ }^{30}$ We have also done the regression for the large window SEK [-10k, 20k]. The results are shown in Table B5 in Appendix B. The findings remain robust.

31 We have performed bunching analyses for European and non-European immigrants based on whether their length of stay is more than 20 years. The analysis shows that the variable 'time since arrival' plays a less important role in this exercise. For immigrants with less than 20 years of stay, the taxable income elasticity as a percentage of the native one is about $92 \%$ and $64 \%$ for European and non-European immigrants respectively. For immigrants with more than 20 years of stay, the corresponding figures are about $82 \%$ and $58 \%$ for European and non-European immigrants respectively. We have also performed the corresponding regression analyses. Again, we find that self-employed non-European immigrants, regardless of length of stay, are less likely to be located in the small bunching window as compared to self-employed natives, whereas bunching behavior of self-employed European immigrants, regardless of length of stay, is statistically similar to self-employed natives.

${ }^{32}$ It has been argued that local social networks affect individual response to welfare take-up through information and through norms, e.g., Bertrand et al. (2000) who use language to proxy for the size of the local social network. For policy makers, the presence of network effects needs to be taken into account as it can strengthen the effect of policies (through multiplier effects) or weaken them, if the network 'pressure' discourages take-up directly or indirectly.
}

grants. ${ }^{33}$ These shares, respectively, constitute a distribution of immigrant shares (at parish level) for the whole of Sweden, separately for European and non-European immigrants. ${ }^{34}$ Using these two distributions, we define, respectively, three immigrant concentration levels with cutoffs at the 25th and 75 th percentile of the distribution. ${ }^{35}$ Thus, we obtain a measure of whether a given self-employed European (non-European) immigrant lives in a parish with low, medium or high concentration of European (non-European) immigrants. As before, the wide income windows for the bunching and regression analysis are SEK [-75k, 75k] and $[-10 \mathrm{k}, 10 \mathrm{k}]$, respectively, but the small bunching window is always [-5k, 5k].

The upper half of Fig. 8 displays bunching estimates of taxable income elasticities for self-employed immigrants relative to natives. The corresponding graphical bunching analysis is shown in Figures B2 and B3 (Appendix B). The elasticity for natives is about 0.041 . For selfemployed European immigrants, the elasticity is close to the native level, but decreasing in the concentration of European immigrants in the parish. For non-European immigrants who live in less segregated areas, the elasticity is close to that of natives, as the upper right panel of Fig. 8 (Low concentration) shows. However, for non-European immigrants living in more segregated areas, the elasticity is only about half of the native elasticity.

Next, we turn to the regression results, which are shown in the bottom half of Fig. 8 (Table B6 in Appendix B contains the results in table form). In all the regressions, natives are the reference group. The estimated coefficients for European immigrants (lower left panel of Fig. 8) are quantitatively small and not statistically significant. For non-European immigrants, we find that those who live in less segregated areas are (statistically) similar to natives in terms of the likelihood of falling into the bunching window SEK [-5k, 5k]. However, nonEuropean immigrants that live in more segregated parishes (medium and high concentration) are about 5 percentage points less likely than self-employed natives to fall into the income interval SEK [ $-5 \mathrm{k}, 5 \mathrm{k}]$. To sum up, the results indicate that immigrants, particularly non-European immigrants, who live in less segregated areas might be better integrated into the host country's society from a tax filing behavior perspective. However, it is also important to point out that we cannot establish causality here, e.g., we do not know whether individual behavior changes when immigrants move into a more or less segregated area. We hope to explore this in future work. ${ }^{36}$

\subsubsection{Organizational form}

Engström and Holmlund (2009) have shown that self-employed individuals with unincorporated businesses differ in their income reporting behavior from self-employed with incorporated businesses. Incorporated firms may use more professional tax planning, but they also tend to have more employees and firm owners, making it more difficult for a single self-employed individual connected to an incorporated firm to

\footnotetext{
33 To be precise, the share is computed as the total number of European (resp. non-European) immigrants divided by the total population in the given parish. 34 The smallest share of European immigrants in any parish is $0.69 \%$ and the largest is $47 \%$. The respective numbers for non-European immigrants are $0.16 \%$ and $46 \%$. The absolute immigrant share of Sweden is $19 \%$ in 2018.

35 These cutoffs can be expressed in terms of absolute immigrant concentration. The numbers are $7 \%$ and $13 \%$ for European immigrants. For non-Europeans they are $5 \%$ and $19 \%$.

36 One possibility would be to use some refugee placement policy (see e.g., Edin et al. 2003, Åslund 2005, and Åslund and Rooth 2007 for Sweden and Damm 2014 for Denmark). The Swedish placement policy occurred in 198791 when the tax system looked quite different as compared to our period of 2002-14 and it is an open question whether it would provide sufficiently strong variation in immigration concentration to highlight differences in tax filing behavior several decades later, given the possibility for people to change location since their initial placement and given our focus on individuals with relatively high incomes.
} 


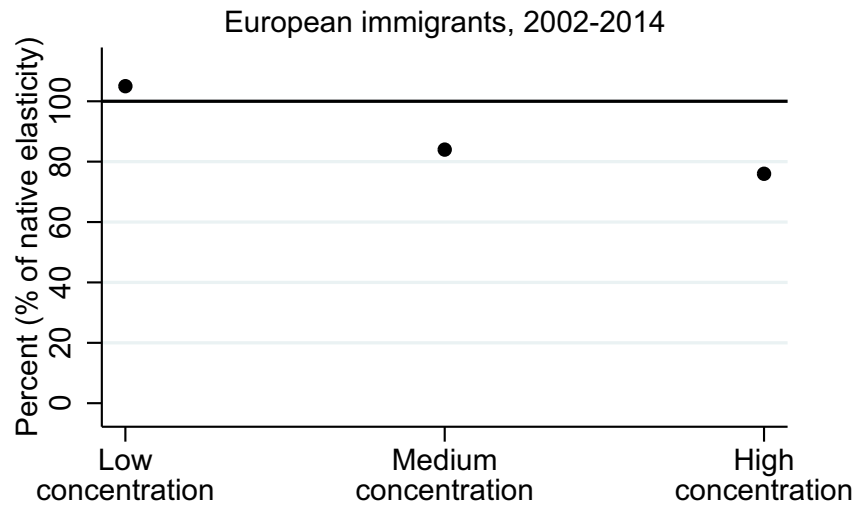

European immigrants, 2002-2014

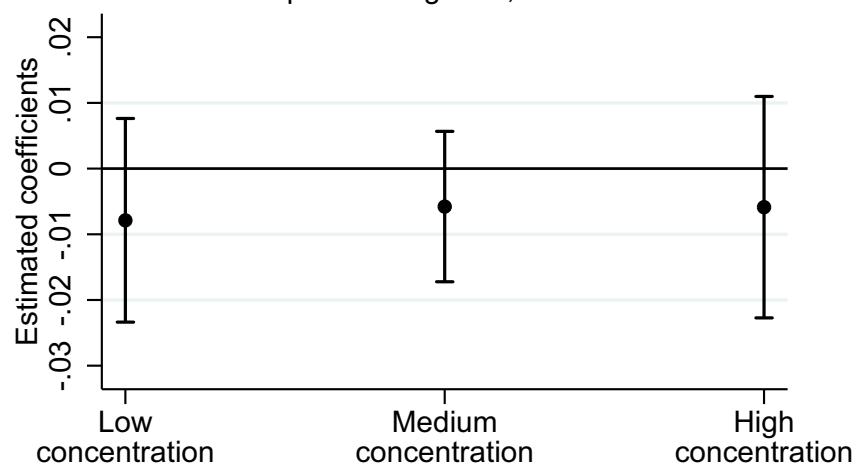

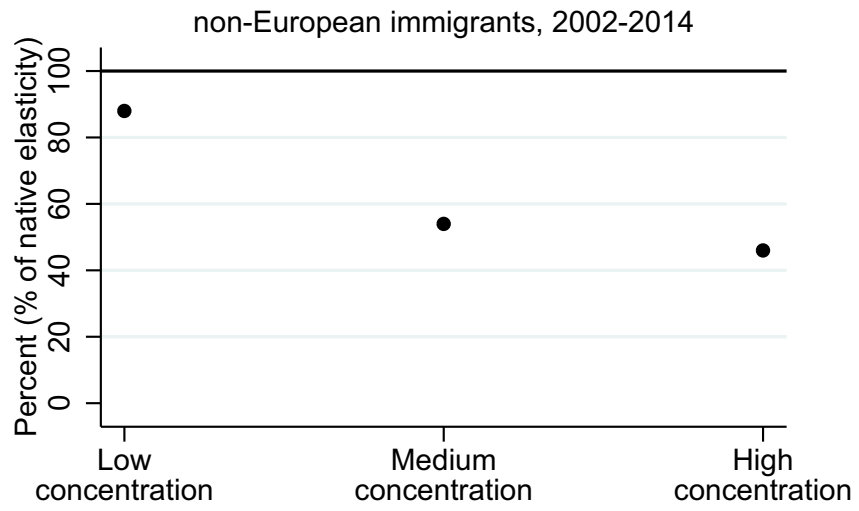

Fig. 8. Residential segregation: Bunching and regression analysis.

perfectly adjust their salary. Hence whether incorporated or unincorporated business owners are more or less likely to bunch at the kink is ambiguous.

In Table B1 (Appendix B, for the wider window [-75k, 75k]), we show summary statistics, describing the composition of our sample with respect to organizational form. We see that about $61 \%$ of selfemployed natives are connected to an incorporated business while the corresponding figures for European and non-European immigrants are about $51 \%$ and $37 \%$. As before, we perform bunching estimation and regressions, in this case focusing only the small bunching window SEK [-5k, 5k].

The upper half of Fig. 9 shows the difference in elasticity between immigrants and natives, divided up by organization form. The corresponding graphical bunching analyses are shown in Figures B4 and B5 (Appendix B). First, consider incorporated businesses. The elasticity for self-employed natives associated with incorporated businesses is about 0.022 , which is smaller than the native elasticity in the baseline results. The corresponding elasticity for European immigrants is close to that of natives, whereas the elasticity for non-European immigrants is only about $60 \%$ of the native. Turning to unincorporated businesses, the elasticity for natives is about 0.074 . The elasticity difference between natives and all immigrants is larger than for incorporated businesses. The taxable income elasticity of non-European immigrants is only half of that of natives. The results show that self-employed people with unincorporated businesses bunch more than those with incorporated businesses. Moreover, the behavioral difference between natives and immigrants is larger among individuals tied to unincorporated firms than among those tied to incorporated firms.

The bottom half of Fig. 9 illustrates the regressions results for the propensity to have a taxable income falling into the small bunching window (the more detailed regression results are presented in Tables
B7 and B8 in Appendix B). Among the self-employed with incorporated businesses, we find that non-European immigrants are about 3 percentage points less likely than natives to fall in the small bunching window. European immigrants, on the other hand, are not statistically significantly different from natives. As regards to unincorporated businesses, we find a large probability difference between non-European immigrants and natives. On average, the probability of having a taxable income falling within the small bunching window for non-European immigrants is about 8 percentage points less than that of natives. The difference between European immigrants and natives is smaller, around 3 percentage points. Thus, the regression results qualitatively support the findings of the bunching estimation.

Appendix B contains supplementary material to this section. Figure $\mathrm{B} 1$ contains the graphical bunching analysis for the baseline case. Table B2 contains more detailed results of the bunching estimation and regressions in table form. Tables B3, B4 and B5 contain sensitivity checks. Table B1 contain summary statistics for the samples used in the bunching estimation and regressions. Figures B2 - B3 show the regression and bunching results for the residential segregation analysis, where Table B6 contains the regression results in table form. Finally, Tables B7 and B8, as well as Figures B4 and B5 provide regression and bunching results for the analysis of the role organizational form.

\subsection{Discussion}

The general picture that emerges from the bunching analysis is that self-employed immigrants exhibit clearly less bunching behavior than native self-employed. There is a substantial difference between European and non-European immigrants, where European immigrants exhibit behavior close to that of natives. There is a clear correlation between the degree of residential segregation and the distance of immi- 

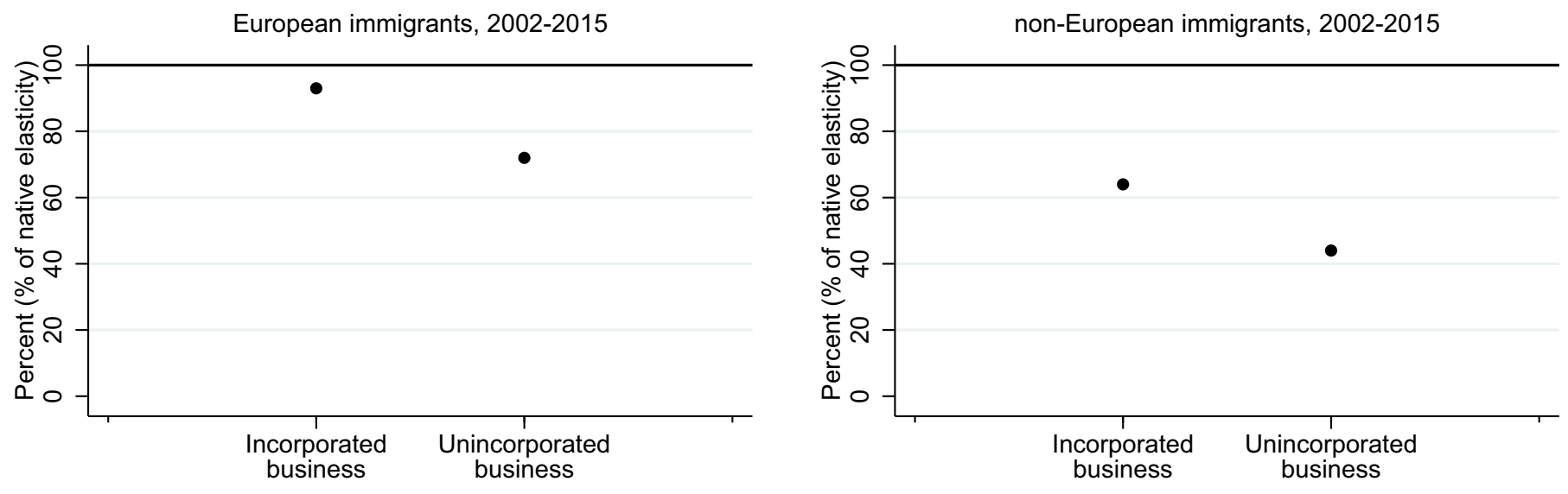

European immigrants, 2002-2015
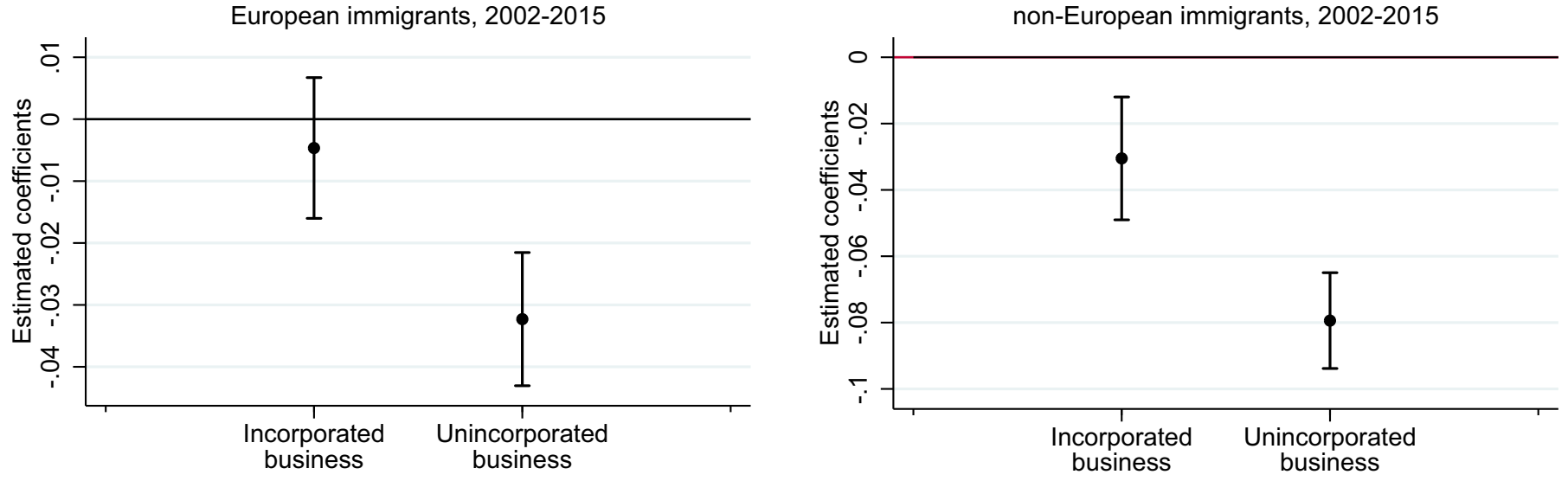

The taxable income elasticity for self-employed native with incorporated and unincorporated business are 0.022 and 0.074 respectively. In the regression analysis, the reference group are self-employed native with incorporated business and with unincorporated business.

Fig. 9. Organizational form: bunching and regression analysis.

grants to native bunching behavior. The distance is furthermore increasing in the residential concentration of immigrants with the same region of origin. This segregation effect is stronger for Non-European self-employed immigrants. A noteworthy exception is non-European immigrants living in low-segregation areas, who are quite close to native bunching behavior. The gap between self-employed natives and immigrants is substantially smaller among those with incorporated businesses, maybe due to reasons relating to higher entry requirements for incorporated businesses and cultures in such businesses regarding formalized tax preparation. Before closing this section, we should mention that the literature on self-employment has highlighted the different forces that may cause individuals to enter self-employment. For example, some are 'pushed' into self-employment due to lack of opportunities in wage employment, others are 'pulled' into self-employment due to business opportunities. Furthermore, the selection process is likely to be different for different immigrant groups, which could explain some of the discrepancies in bunching behavior between natives and immigrants that we have found. Here it should be noted that we focus on high income groups in the population that arguably have decent opportunities both in wage employment and self-employment. However, some obstacles to finding wage employment, such as labor market discrimination, could be relevant also for highly skilled groups of the population. ${ }^{37}$

\footnotetext{
${ }^{37}$ See Hammarstedt and Miao (2019) for a recent analysis of self-employment in Sweden.
}

\section{Further results}

In this final section, we present some further results regarding differences in tax filing behavior between natives and immigrants. We focus on three different measures. First, we look at whether or not individuals have been fined for submitting their tax declaration after the deadline. The Swedish Tax Agency imposes a fee for late filing where the fee typically is between 1000 and 3000 SEK. Second, we examine the incidence of audits. The tax authority runs audits of tax declarations, and in case of incorrect filing, imposes penalties of around $20-40 \%$ of the unpaid tax. Third, we examine the difference between the preliminary income tax amount sent to the taxpayer by the authority and the final tax amount. Whether or not these two amounts are different provides a measure of the taxpayer's active participation in income reporting: If the amounts differ, the taxpayer has made additional declarations. If the amounts are equal, the taxpayer either had nothing to declare in addition, or has not exercised that option. As mentioned earlier, the tax authority grants early tax returns for taxpayers who accept the preliminary tax statement without asking for additional tax deductions. In all these exercises, we focus on the whole immigrant population, which includes both low income and high income taxpayers.

We create three binary variables: (i) whether the taxpayer has been engaged in late tax filing; (ii) whether the authority has imposed tax surcharges for incorrect tax filing; and (iii) whether the taxpayer is not actively participating in the tax declaration. A taxpayer is defined as not actively participating in the tax declaration if the preliminary tax is equal to the final tax. Using these three variables as dependent variables, 
we examine the effect of immigrant status (and origin), using natives as the reference group. We employ a linear probability model, controlling for age, gender, education attainment, marital status, total taxable income, municipality and a year fixed effect.

We find that immigrants have a larger probability of filing their taxes late, independently of their length of stay in the host country. When differentiating by income (in three groups, divided by the 25th, 50th, and 75th percentile), we find one exception to this pattern. Low income immigrants (except for Nordic immigrants) behave similar to natives, although the estimated coefficients are not economically significant (see Figure C1 in Appendix C).

We find that immigrants have a higher propensity for noncompliance (as measured by the audit measure), regardless of length of stay. As we see in Figure C2 in Appendix C, there is again an exception for low-income European and non-European immigrants: they are similar to natives. Moreover, tax non-compliance increases with income for non-European immigrants (see Figure C2, lower left panel). Differentiating the population according to the composition of their income sources, we find that the difference in tax non-compliance between natives and immigrants is substantially larger for those with business income. All these results should be interpreted with caution, as we have no information about how the tax authority selects taxpayers to be audited.

Finally, we find that immigrants are less likely to actively participate in income declaration (see Figure C3 in Appendix C). There is a very clear trend with respect to length of stay in the host country: Immigrants close most of the gap over time (even when controlling for total taxable income), but there remains a difference even after more than 10 years in the country. The gap remains the largest for non-European immigrants.

\section{Concluding remarks}

In this paper, we have analyzed differences in tax filing behavior between natives and immigrants using population-wide data from Sweden and two specific empirical examples.

Our first empirical example examined the difference in the take-up of commuting deductions between immigrants and natives, controlling for a rich set of covariates. We found that immigrants with a longer stay in the host country (independent of origin) and immigrants from Nordic and European countries, behave more like natives whereas the differences are strongest for non-European immigrants who have recently arrived in the host country. The gap to natives is closed over time, and the gap is closed completely for individuals with more than 10 years in the host country. Interestingly, immigrants with the longest stay in the host country file even more than natives.

Our second empirical exercise examined differences between natives and immigrants in terms of the extent of bunching among the self-employed in response to a very large and salient kink point of the Swedish income tax schedule. These bunching responses, that reflect causal responses to the tax system, show that there are striking differences in tax filing behavior between natives and immigrants, even for immigrant self-employed who have stayed in Sweden for a long time. Moreover, we have seen that differences in bunching behavior between natives and immigrants are strongly correlated with residential segregation. This is especially the case when examining non-European immigrants. An interesting exception is non-European immigrants living in low-segregation areas, who behave similar to natives. We do not, however, know whether our results are driven by selection into these areas, or whether there are true exposure effects as documented by, e.g., Chetty et al. (2013).

We complemented our study examining several measures of tax compliance for the whole population of Swedish taxpayers. Immigrants are more likely to miss the declaration deadline and to be fined for noncompliance, regardless of their length of stay in the country. An exception are low-income immigrants whose behavior is not significantly different from that of natives. Immigrants are also less likely to actively participate in the tax declaration process (through the filing of deductions etc.), but most of this gap closes over time.

Several remarks are in order. First, immigration to Sweden has not been homogeneous over time in terms of source countries, skills and migration motives, just to name a few relevant aspects. We have set out to document differences in behavior between immigrants and natives regarding tax filing behavior in one particular time window, but we have not explicitly studied the process of convergence in tax filing behavior between natives and immigrants by following individuals over time. A large body of work in the migration literature has studied the process of assimilation and immigrant's economic convergence towards natives. In the US context, this research has shown that earlier cohorts of immigrants assimilate faster towards natives than later cohorts due to differences in earnings abilities (see, e.g., Borjas 1995). In our context, these cohort effects are likely to be less important, and our results are potentially easier to generalize to other contexts, since in both our empirical examples, we focus on samples of immigrants and natives that have high incomes (and are thereby integrated into the labor market) and share a similarly high education background. Second, our study documents differences in tax filing behavior, but cannot address the issue of tax evasion or cheating. In that sense, a part of the documented behavioral differences might be differences in tax evasion. However, regardless of the cause of the behavioral differences, the fairness of taxation is affected and the consequences of a low take up are materialized. Third, there seems to be scope for policy intervention (we refer to some successful policy measures in the literature section), such as alleviating language barriers for recently arrived immigrants, but a range of open questions remain, e.g., whether or not segregation and network effects cause the observed differences in tax filing behavior that we have documented, or why a substantial gap in bunching behavior remains even after a very long time in the host country. We hope to address these questions in future research.

The primary focus of our paper has been to analyze the differential take-up by informed (native) and less informed (immigrant) workers, highlighting the effects of tax complexity on take-up in ethnically diverse populations. We have not formally analyzed the impact of differential take-up on equilibrium spatial patterns in labor markets. This is an important research question with implications for a range of different aspects, such as labor supply, the formation of ethnic enclaves, urban sprawl and the quality of employer-employee matching. A formal analysis of such effects may be possible using our policy context, but is left as another interesting direction for future research.

\section{Declaration of Competing Interest}

The authors declare that they have no conflict of interest.

\section{Supplementary material}

Supplementary material associated with this article can be found, in the online version, at 10.1016/j.jue.2019.103215.

\section{References}

Åslund, O., 2005. Now and forever? Initial and subsequent location choices of immigrants. Reg. Sci. Urban Econ. 35, 141-165. doi:10.1016/j.regsciurbeco.2004.02.001.

Åslund, O., Rooth, D., 2007. Do when and where matter? Initial labour market conditions and immigrant earnings. Econ. J. 117, 422-448. doi:10.1111/j.1468-0297.2007.02024.x.

Abeler, J., Jäger, S., 2015. Complex tax incentives. Am. Econ. J.: Econ. Policy 7, 1-28. doi:10.1257/pol.20130137.

Aftonbladet.se, 2018. Då Har du Rätt Att Göra Reseavdrag. https://www.aftonbladet se/minekonomi/a/kaMovk/da-har-du-ratt-att-gora-reseavdrag

Aghion, P., Akcigit, U., Lequien, M., Stantcheva, S., 2018. Tax Simplicity and Heterogeneous Learning. Banque de France Working Paper \#665

Allcott, H., Lockwood, B.B., Taubinsky, D., 2019. Regressive Sin Taxes, with an Application to the Optimal Soda Tax. NBER Working Paper No. 25841

Allingham, M.G., Sandmo, A., 1972. Income tax evasion: a theoretical analysis. J. Public Econ. 1, 323-338. doi:10.1016/0047-2727(72)90010-2. 
Alstadsæter, A., Jacob, M., 2017. Who participates in tax avoidance? Evidence from Swedish microdata. Appl. Econ. 49, 2779-2796. doi:10.1080/00036846.2016.1248285.

Alstadsæter, A., Kopczuk, W., Telle, K., 2018. Social Networks and Tax Avoidance: Evidence from a Well-Defined Norwegian Tax Shelter. NBER Working Paper No. 25191

Bargain, O., Immervoll, H., Viitamäki, H., 2012. No claim, no pain. Measuring the non-take-up of social assistance using register data. J. Econ. Inequal. 10, 375-395. doi:10.1007/s10888-010-9158-8.

Bastani, S., Selin, H., 2014. Bunching and non-bunching at kink points of the Swedish tax schedule. J. Public Econ. 109, 36-49. doi:10.1016/j.jpubeco.2013.09.010.

Baum-Snow, N., Kahn, M.E., 2000. The effects of new public projects to expand urban rail transit. J. Public Econ. 77, 241-263. doi:10.1016/S0047-2727(99)00085-7.

Benzarti, Y., 2017. How Taxing is Tax Filing? Using Revealed Preferences to Estimate Compliance Costs. NBER Working Paper No. 23903

Bernheim, B.D., Taubinsky, D., 2018. Chapter 5 - Behavioral public economics. In: Bernheim, B.D., DellaVigna, S., Laibson, D. (Eds.), Handbook of Behavioral Economics Foundations and Applications 1. In: Handbook of Behavioral Economics: Applications and Foundations 1, vol. 1. North-Holland, pp. 381-516.

Bertrand, M., Luttmer, E.F., Mullainathan, S., 2000. Network effects and welfare cultures. Q. J. Econ. 115, 1019-1055. doi:10.1162/003355300554971.

Bezin, E., Moizeau, F., 2017. Cultural dynamics, social mobility and urban segregation. J. Urban Econ. 99, 173-187. doi:10.1016/j.jue.2017.02.004.

Bhargava, S., Manoli, D., 2015. Psychological frictions and the incomplete take-up of social benefits: evidence from an IRS field experiment. Am. Econ. Rev. 105, 3489-3529. doi:10.1257/aer.20121493.

Black, D.A., Kolesnikova, N., Taylor, L.J., 2014. Why do so few women work in New York (and so many in Minneapolis)? Labor supply of married women across US cities. J. Urban Econ. 79, 59-71. doi:10.1016/j.jue.2013.03.003.

Blumkin, T., Kosonen, T., Kotakorpi, K., 2019. Complexity and Benefit Take-Up: Empirical Evidence from the Finnish Homecare Allowance. Working Paper

Bohne, A., Nimczik, J.S., et al., 2018. Information Frictions and Learning Dynamics: Evidence from Tax Avoidance in Ecuador. IZA Discussion Paper No. 11536

Borjas, G.J., 1995. Assimilation and changes in cohort quality revisited: what happened to immigrant earnings in the 1980s? J. Labor Econ. 13, 201-245. doi:10.1086/298373.

Boustan, L.P., Margo, R.A., 2009. Race, segregation, and postal employment: new evidence on spatial mismatch. J. Urban Econ. 65, 1-10. doi:10.1016/j.jue.2008.08.002.

Buhlmann, F., Elsner, B., Peichl, A., 2018. Tax refunds and income manipulation: evidence from the EITC. Int. Tax Public Finance 25, 1490-1518. doi:10.1007/s10797-018-9510-7.

Chetty, R., Friedman, J.N., Olsen, T., Pistaferri, L., 2011. Adjustment costs, firm responses, and micro vs. macro labor supply elasticities: evidence from Danish tax records. Q. J. Econ. 126, 749-804. doi:10.1093/qje/qjr013.

Chetty, R., Friedman, J.N., Saez, E., 2013. Using differences in knowledge across neighborhoods to uncover the impacts of the EITC on earnings. Am. Econ. Rev. 103, 26832721. doi:10.1257/aer.103.7.2683.

Chetty, R., Looney, A., Kroft, K., 2009. Salience and taxation: theory and evidence. Am. Econ. Rev. 99, 1145-1177. doi:10.1257/aer.99.4.1145.

Chetty, R., Saez, E., 2013. Teaching the tax code: earnings responses to an experiment with EITC recipients. Am. Econ. J.: Appl. Econ. 5, 1-31. doi:10.1257/app.5.1.1.

Damm, A.P., 2014. Neighborhood quality and labor market outcomes: evidence from quasi-random neighborhood assignment of immigrants. J. Urban Econ. 79, 139-166. doi:10.1016/j.jue.2013.08.004.

De la Roca, J., 2017. Selection in initial and return migration: evidence from moves across Spanish cities. J. Urban Econ. 100, 33-53. doi:10.1016/j.jue.2017.04.004.

Doerrenberg, P., Peichl, A., Siegloch, S., 2017. The elasticity of taxable income in the presence of deduction possibilities. J. Public Econ. 151, 41-55. doi:10.1016/j.jpubeco.2015.10.001.

Drago, F., Mengel, F., Traxler, C., 2019. Compliance behavior in networks: Evidence from a field experiment. American Economic Journal: Applied Economics doi:10.1257/app.20170690. (forthcoming).

Edin, P.A., Fredriksson, P., Åslund, O., 2003. Ethnic enclaves and the economic success of immigrants-evidence from a natural experiment. Q. J. Econ. 118, 329-357. doi:10.1162/00335530360535225.

Edmark, K., Gordon, R., 2013. Taxes and the Choice of Organizational form by Entrepreneurs in Sweden. IFN Working Paper No. 982

Engström, P., Holmlund, B., 2009. Tax evasion and self-employment in a high-tax country: evidence from Sweden. Appl. Econ. 41, 2419-2430. doi: $10.1080 / 00036840701765452$.

Engström, P., Nordblom, K., Ohlsson, H., Persson, A., 2015. Tax compliance and loss aversion. Am. Econ. J.: Econ. Policy 7, 132-164. doi:10.1257/pol.20130134.

Engström, P., Nordblom, K., Stefánsson, A., 2018. Multiple Misbehaving: Loss Averse and Inattentive to Monetary Incentives. Working Paper

Feldman, N.E., Katu ščák, P., Kawano, L., 2016. Taxpayer confusion: evidence from the child tax credit. Am. Econ. Rev. 106, 807-835. doi:10.1257/aer.20131189.

Fjeldstad, O.H., Heggstad, K., 2012. Building Taxpayer Culture in Mozambique, Tanzania and Zambia: Achievements, Challenges and Policy Recommendations. CMI Report

Friedrichsen, J., König, T., Schmacker, R., 2018. Social image concerns and welfare takeup. J. Public Econ. 168, 174-192. doi:10.1016/j.jpubeco.2018.10.008.

Frimmel, W., Halla, M., Paetzold, J., 2018. The intergenerational causal effect of tax evasion: evidence from the commuter tax allowance in Austria. J. Eur. Econ. Assoc. doi:10.1093/jeea/jvy033.

Gabriel, S.A., Rosenthal, S.S., 1996. Commutes, neighborhood effects, and earnings: an analysis of racial discrimination and compensating differentials. J. Urban Econ. 40, 61-83. doi:10.1006/juec.1996.0023.
Garcia-López, M.A., 2012. Urban spatial structure, suburbanization and transportation in Barcelona. J. Urban Econ. 72, 176-190. doi:10.1016/j.jue.2012.05.003.

Garcia-López, M.A., Holl, A., Viladecans-Marsal, E., 2015. Suburbanization and highways in Spain when the Romans and the Bourbons still shape its cities. J. Urban Econ. 85, 52-67. doi:10.1016/j.jue.2014.11.002.

Glaeser, E.L., Rosenthal, S.S., Strange, W.C., 2010. Urban economics and entrepreneurship. J. Urban Econ. 67, 1-14. doi:10.1016/j.jue.2009.10.005.

Guyton, J., Manoli, D.S., Schafer, B., Sebastiani, M., 2016. Reminders \& Recidivism: Evidence from Tax Filing \& EITC Participation Among Low-Income Nonfilers. NBER Working Paper No. 21904

Gutiérrez-i Puigarnau, E., van Ommeren, J.N., 2010. Labour supply and commuting. J. Urban Econ. 68, 82-89. doi:10.1016/j.jue.2010.03.003.

Hammarstedt, M., Miao, C., 2019. Self-employed immigrants and their employees: evidence from Swedish employer-employee data. Rev. Econ. Househ. doi:10.1007/s11150-019-09446-1.

Hansen, J., Lofstrom, M., 2003. Immigrant assimilation and welfare participation do immigrants assimilate into or out of welfare? J. Hum. Resour. 38, 74-98. doi:10.3368/jhr.XXXVIII.1.74.

Hensen, M.M., De Vries, M.R., Cörvers, F., 2009. The role of geographic mobility in reducing education-job mismatches in the Netherlands. Pap. Reg. Sci. 88, 667-682. doi:10.1111/j.1435-5957.2008.00189.x.

Heuermann, D.F., Assmann, F., vom Berge, P., Freund, F., 2017. The distributional effect of commuting subsidies - evidence from geo-referenced data and a large-scale policy reform. Reg. Sci. Urban Econ. 67, 11-24. doi:10.1016/j.regsciurbeco.2017.08.001.

Hoopes, J.L., Reck, D.H., Slemrod, J., 2015. Taxpayer search for information: implications for rational attention. Am. Econ. J.: Econ. Policy 7, 177-208. doi:10.1257/pol.20140050.

Kleven, H.J., Knudsen, M.B., Kreiner, C.T., Pedersen, S., Saez, E., 2011. Unwilling or unable to cheat? Evidence from a tax audit experiment in Denmark. Econometrica 79, 651-692. doi:10.3982/ECTA9113.

Kleven, H.J., Waseem, M., 2013. Using notches to uncover optimization frictions and structural elasticities: theory and evidence from Pakistan. Q. J. Econ. 128, 669-723. doi:10.1093/qje/qjt004.

Le Gallo, J., L'Horty, Y., Petit, P., 2017. Does enhanced mobility of young people improve employment and housing outcomes? Evidence from a large and controlled experiment in France. J. Urban Econ. 97, 1-14. doi:10.1016/j.jue.2016.10.003.

Lockwood, B.B., 2017. Optimal Income Taxation with Present Bias. University of Pennsylvania Working Paper.

Luttmer, E.F., Singhal, M., 2014. Tax morale. J. Econ. Perspect. 28, 149-168. doi:10.1257/jep.28.4.149.

Manoli, D.S., Turner, N., 2014. Nudges and Learning: Evidence from Informational Interventions for Low-Income Taxpayers. NBER Working Paper No. 20718

Mascagni, G., 2018. From the lab to the field: a review of tax experiments. J. Econ. Surv. 32, 273-301. doi:10.1111/joes.12201.

Mayer, T., Trevien, C., 2017. The impact of urban public transportation evidence from the Paris region. J. Urban Econ. 102, 1-21. doi:10.1016/j.jue.2017.07.003.

Paetzold, J., 2019a. Do commuting subsidies increase commuting distances? Evidence from a regression kink design. Reg. Sci. Urban Econ. 75, 136-147.

Paetzold, J., 2019b. How do taxpayers respond to a large kink? Evidence on earnings and deduction behavior from Austria. Int. Tax Public Finance 26 (1), 167-197.

Paetzold, J., Winner, H., 2016. Taking the high road? Compliance with commuter tax allowances and the role of evasion spillovers. J. Public Econ. 143, 1-14. doi:10.1016/j.jpubeco.2016.08.001.

Potter, S., Enoch, M., Rye, T., Black, C., Ubbels, B., 2006. Tax treatment of employer commuting support: an international review. Transport Rev. 26, 221-237. doi:10.1080/01441640500184385.

Ramnath, S.P., Tong, P.K., 2017. The persistent reduction in poverty from filing a tax return. Am. Econ. J.: Econ. Policy 9, 367-394. doi:10.1257/pol.20150486.

Robles, B., 2009. A tax education and asset building campaign for low-income and limited-English worker populations: lessons from four states, TY 2004 - TY 2007. In: Recent Research on Tax Administration and Compliance: Selected Papers given at the 2009 IRS Research Conference. IRS Research Bulletin, pp. 227-252.

Rosenthal, S.S., Strange, W.C., 2008. The attenuation of human capital spillovers. J. Urban Econ. 64, 373-389. doi:10.1016/j.jue.2008.02.006.

Saez, E., 2009. Details matter: the impact of presentation and information on the take-up of financial incentives for retirement saving. Am. Econ. J.: Econ. Policy 1, 204-228. doi:10.1257/pol.1.1.204.

Saez, E., 2010. Do taxpayers bunch at kink points? Am. Econ. J.: Econ. Policy 2, 180-212. doi:10.1257/pol.2.3.180

Skatteverket, 2018. Ny tjÄnst rÄknar ut om du har Rätt Till Reseavdrag (Skatteverkets Pressmeddelande). https://www.skatteverket.se/omoss/press/pressmeddelanden/ 2018/2018/nytjanstraknarutomduharratttillreseavdrag.5. 41f1c61d16193087d7fbbe9.html

Slemrod, J., 2007. Cheating ourselves: the economics of tax evasion. J. Econ. Perspect. 21, 25-48. doi:10.1257/jep.21.1.25.

Taubinsky, D., Rees-Jones, A., 2018. Attention variation and welfare: theory and evidence from a tax salience experiment. Rev. Econ. Stud. 85, 2462-2496. doi:10.1093/restud/rdx069.

Zenou, Y., 2013. Spatial versus social mismatch. J. Urban Econ. 74, 113-132. doi:10.1016/j.jue.2012.11.002. 